\title{
Article \\ Probing the Structure and Function of the Cytosolic Domain of the Human Zinc Transporter ZnT8 with Nickel(II) Ions
}

\author{
Maria Carmen Catapano ${ }^{1,2}{ }^{\oplus}$, Douglas S. Parsons ${ }^{1,3}{ }^{\oplus}$, Radosław Kotuniak ${ }^{4}$, Přemysl Mladěnka ${ }^{5} \oplus$, \\ Wojciech Bal ${ }^{4}$ and Wolfgang Maret ${ }^{1, *}$ \\ 1 Departments of Biochemistry and Nutritional Sciences, School of Life Course Sciences, Faculty of Life \\ Sciences and Medicine, King's College London, Franklin-Wilkins Bldg, 150 Stamford St., \\ London SE1 9NH, UK; catapanm@faf.cuni.cz (M.C.C.); parsonsd@bu.edu (D.S.P.) \\ 2 Department of Analytical Chemistry, Faculty of Pharmacy in Hradec Králové, Charles University, \\ Heyrovského 1203, 50005 Hradec Králové, Czech Republic \\ 3 Department of Radiology, Boston University School of Medicine, 670 Albany Street, Boston, MA 02118, USA \\ 4 Institute of Biochemistry and Biophysics, Polish Academy of Sciences, Pawińskiego 5a, \\ 02-106 Warsaw, Poland; r.kotuniak@ibb.waw.pl (R.K.); wojciech.bal.ibb@gmail.com (W.B.) \\ 5 Department of Pharmacology and Toxicology, Faculty of Pharmacy in Hradec Králové, Charles University, \\ Heyrovského 1203, 50005 Hradec Králové, Czech Republic; mladenkap@faf.cuni.cz \\ * Correspondence: wolfgang.maret@kcl.ac.uk; Tel.: +44-(0)20-7848-4264
}

check for updates

Citation: Catapano, M.C.; Parsons, D.S.; Kotuniak, R.; Mladěnka, P.; Bal, W.; Maret, W. Probing the Structure and Function of the Cytosolic Domain of the Human Zinc Transporter ZnT8 with Nickel(II) Ions. Int. J. Mol. Sci. 2021, 22, 2940. https: / / doi.org/10.3390/ ijms22062940

Academic Editor: Taiho Kambe

Received: 1 March 2021

Accepted: 9 March 2021

Published: 14 March 2021

Publisher's Note: MDPI stays neutral with regard to jurisdictional claims in published maps and institutional affiliations.

Copyright: (c) 2021 by the authors. Licensee MDPI, Basel, Switzerland. This article is an open access article distributed under the terms and conditions of the Creative Commons Attribution (CC BY) license (https:// creativecommons.org/licenses/by/ $4.0 /)$.
Abstract: The human zinc transporter ZnT8 provides the granules of pancreatic $\beta$-cells with zinc (II) ions for assembly of insulin hexamers for storage. Until recently, the structure and function of human ZnTs have been modelled on the basis of the 3D structures of bacterial zinc exporters, which form homodimers with each monomer having six transmembrane $\alpha$-helices harbouring the zinc transport site and a cytosolic domain with an $\alpha, \beta$ structure and additional zinc-binding sites. However, there are important differences in function as the bacterial proteins export an excess of zinc ions from the bacterial cytoplasm, whereas ZnT8 exports zinc ions into subcellular vesicles when there is no apparent excess of cytosolic zinc ions. Indeed, recent structural investigations of human ZnT8 show differences in metal binding in the cytosolic domain when compared to the bacterial proteins. Two common variants, one with tryptophan (W) and the other with arginine (R) at position 325, have generated considerable interest as the R-variant is associated with a higher risk of developing type 2 diabetes. Since the mutation is at the apex of the cytosolic domain facing towards the cytosol, it is not clear how it can affect zinc transport through the transmembrane domain. We expressed the cytosolic domain of both variants of human ZnT8 and have begun structural and functional studies. We found that (i) the metal binding of the human protein is different from that of the bacterial proteins, (ii) the human protein has a C-terminal extension with three cysteine residues that bind a zinc(II) ion, and (iii) there are small differences in stability between the two variants. In this investigation, we employed nickel(II) ions as a probe for the spectroscopically silent $\mathrm{Zn}$ (II) ions and utilised colorimetric and fluorimetric indicators for $\mathrm{Ni}(\mathrm{II})$ ions to investigate metal binding. We established $\mathrm{Ni}$ (II) coordination to the C-terminal cysteines and found differences in metal affinity and coordination in the two ZnT8 variants. These structural differences are thought to be critical for the functional differences regarding the diabetes risk. Further insight into the assembly of the metal centres in the cytosolic domain was gained from potentiometric investigations of zinc binding to synthetic peptides corresponding to N-terminal and C-terminal sequences of ZnT8 bearing the metalcoordinating ligands. Our work suggests the involvement of the C-terminal cysteines, which are part of the cytosolic domain, in a metal chelation and/or acquisition mechanism and, as now supported by the high-resolution structural work, provides the first example of metal-thiolate coordination chemistry in zinc transporters.

Keywords: zinc transporter; ZnT8; C-terminal domain; zinc; nickel; diabetes type 2 


\section{Introduction}

A subgroup of four out of ten human zinc transporters (ZnT2, 3, 4 and 8) of the cation diffusion facilitator (CDF) protein family exports $\mathrm{Zn}^{2+}$ ions from the cytosol into intracellular vesicles [1,2]. One of the four, ZnT8 (SLC30A8), is highly expressed in the membrane of the dense insulin secretory granules of pancreatic $\beta$-cells, where it supplies zinc(II) ions for the storage of insulin as a crystalline hexamer and for other aspects of granule biochemistry [3]. ZnT8 is also present in $\alpha$-cells of the endocrine pancreas, but its precise role in glucagon secretion has not yet been elucidated [4].

Concepts of how these vesicular zinc transporters work were primarily based on the 3D structures of prokaryotic CDF proteins. The crystal structure of the Escherichia coli protein YiiP revealed a homodimer with a transmembrane domain (TMD) and a cytosolic C-terminal domain (CTD) [5]. The dimer binds eight $\mathrm{Zn}$ (II) ions: two in sites A, which are the primary TMD transport sites, two in sites $B$ between the domains and with an unknown function, and four in the binuclear sites $C$ at the dimer interface of the CTDs. The CTDs in E. coli YiiP are believed to be metal ion sensors, working by an allosteric mechanism such that the occupancy of sites $C$ with zinc induces a conformational change of the CTD, which is then transmitted to the TMD for triggering zinc/proton antiport [6]. A cryogenic electron microscopy structure of a YiiP homologue from Shewanella oneidensis, however, does not confirm the allosteric mechanism of zinc binding, but rather suggests that $\mathrm{Zn}$ (II) ions are bound to the CTD with such high affinity as to be considered structurally stabilizing for the dimer as a whole [7]. Aside from YiiP, there are currently crystal structures of bacterial CTDs from Thermus thermophilus CzrB [8], Thermotoga maritima TM0876 [9], Magnetospira sp. MamB [10], Magnetospirillum gryphiswaldense MamM [11], and CzcD proteins from T. thermophilus, Pseudomonas aeruginosa and Cupriavidus metallidurans [12]. The structural models of the bacterial proteins fail to explain the function(s) of the CTD in the mammalian family of vesicular transporters. While the bacterial proteins sense and export an excess of zinc, there is no evidence for an excess of zinc in the cytosol of eukaryotic cells for export into granules of the secretory pathway. While total cellular zinc concentrations are about $250 \mu \mathrm{M}$, the $\mathrm{Zn}$ (II) ion concentration available to fluorescent probes and sensors is only hundreds of pM to maximally $1.5 \mathrm{nM}[13,14]$. In granules, estimates of $\mathrm{Zn}^{2+}$ ion concentrations are $120 \mathrm{nM}$ (pH 6) and total $\mathrm{Zn}$ (II) concentrations are tens to perhaps even hundreds of $\mathrm{mM}[15,16]$. The $\mathrm{Zn}(\mathrm{II})$ ion concentration thus measured have been variously referred to accessible, buffered, labile, available or "free" zinc with each of these attributes having limitations and/or being misleading in the implied meaning. Given the abundance of low molecular weight ligands in the cell, there are no $\mathrm{Zn}^{2+}$ ions with water ligands only in the cytosol, but several $\mathrm{nM}$ of zinc bound to small molecules with an overall approximate affinity of $100 \mathrm{fM}$ [17]. Independent of these fundamental issues, there is no excess of zinc freely available for passive transmembrane transport. Additional issues for interpreting gradients across the membrane of granules are that given an average granule volume of only $7.2 \mathrm{aL}$, the estimated $\mathrm{Zn}^{2+}$ concentration of $120 \mathrm{nM}$ would indicate less than one $\mathrm{Zn}^{2+}$ ion per granule, and that crystallization of insulin will further reduce the concentration in solution as it removes zinc from equilibria in solution [18].

It is also the case that the protective effects of bacterial export proteins may not require a constitutively active protein, and so an allosteric mechanism relying on a toxic excess of cytosolic zinc fulfils the necessary function in bacteria. Conversely, mammalian vesicular ZnTs must supply their secretory granules with zinc under 'normal' tightly controlled cytosolic zinc, and thus a simple allosteric mechanism reliant on increased cytosolic zinc may not be possible.

Two cryo-EM investigations of human ZnT8, one at relatively low resolution (about $20 \AA$ ) and another at relatively high resolution (about $4 \AA$ ), have now provided additional insights $[19,20]$ and confirm the differences we noted in zinc binding of the CTD compared to the bacterial YiiP protein and the involvement of the C-terminal cysteines in zinc binding [21]. The metal sensing mechanism of the CTD discussed for the YiiP protein is based on the presence of two pairs of binuclear metal ion sites at the dimer interface. Each 
$\mathrm{Zn}$ (II) ion is bound by a pair of two His residues and a bridging Asp side chain from the second subunit. A trinuclear site $\mathrm{C}$ has been observed in the bacterial CzrB protein [8] and one, two, or three metal binding sites have been observed in the $\mathrm{CzcD}$ proteins [12]. Our analysis showed that in the human vesicular ZnTs, the ligands for binding of the second metal ion, including the bridging Asp, are not strictly conserved [21]. The conservation of only three potential ligands in the vesicular zinc transporters raises the questions of whether the CTDs in these transporters sense Zn(II) concentrations and how the monomers interact in the dimer. Related to the nature of the interface metal site is the question of how zinc is delivered to and from the transporter as cellular zinc traffic is tightly regulated and all $\mathrm{Zn}$ (II) ions are bound to biological ligands [17]. The protein fold of the CTD resembles that of copper metallochaperones [5]. Thus, does the CTD have the function of a chaperone for delivery of zinc or is it interacting with a putative metallochaperone to acquire zinc? Rather than solving these questions, the remarkably different zinc binding of the CTD of human ZnT8 involving both the N-terminus of the transmembrane domain and the C-terminus of the CTD puts new emphasis on their future resolution [20].

A structural issue of ZnT8 with significant functional implications is a point mutation at position 325 in the CTD. It results in two variants with either $\operatorname{Arg}(\mathrm{R})$ or $\operatorname{Trp}(\mathrm{W})$, both of which are common in human populations (R: 60-95\%; W: 5-40\%) [22]. Remarkably, the major R-variant increases the risk of developing type 2 diabetes [3]. The transport activity of the R-variant was found to be higher than that of the W-variant [23], lower [24] or no difference was observed [25], leaving the question unanswered as to whether less or more zinc in the insulin granules is favourable to $\beta$-cell health. A computational investigation has now shown that the two amino acids differentially affect zinc coordination sites in the TMD [26]. They affect the orientation of the transmembrane (TM) helices 4 and 5, which increases the distances for the zinc ligands (Asp)D110 and D224 in site A in the W-variant. Furthermore, (Glu)E88, moves closer to site A. E88 together with D103 are thought to serve as ligands of the zinc(II) ion once it moves away from the two histidine ligands (H106 and H220) in site A. The two ZnT8 variants are targeted by different autoantibodies in type 1 diabetes, indicating that the mutation also affects epitope formation, although there is no apparent change in type 1 diabetes risk [27]. Thus, characterizing the CTDs of ZnT8 functionally in terms of metal binding would solve a key issue in $\beta$-cell granule biology, provide important information regarding the biology of other zinc-containing vesicles served by ZnT2-4, and make a significant contribution to CDF biology in general with wide implications.

In this work, we expressed both common CTD variants of ZnT8 and employed their nickel binding as spectroscopic probes for their structures. We describe differences in metal affinities and coordination of the two variants and establish for the first time an important structural difference between the variants. We also further characterized metal binding to the ZnT8 C-terminal cysteines using both recombinant CTD protein and a synthetic peptide of the C-terminus. The low nanomolar affinity of the peptide for $\mathrm{Zn}$ (II) suggests that the C-terminus, but not the N-terminus, which binds zinc with an affinity lower by two orders of magnitude, could be involved in a "swinging arm mechanism" in which the C-terminus in the extended conformation acquires zinc from a zinc donor and then swings over to form the metal site with the other ligands for allosteric regulation of zinc transport. In agreement with the recent 3D structural work on human ZnT8, our investigations confirm the novel involvement of metal-sulfur interactions in the biochemistry of zinc transporter proteins.

\section{Results}

\subsection{Stability of the ZnT8 CTDs}

Since we noticed a propensity of the $\mathrm{ZnT} 8 \mathrm{c}$ proteins to aggregate within days of purification [21], we examined ways to store the protein. The protein was stored at $-20{ }^{\circ} \mathrm{C}$ with a solution containing $50 \%(v / v)$ glycerol for up to three months, subjected to several freeze-thaw cycles and then used immediately after thawing. Following thawing, the protein was briefly and lightly vortex-mixed and centrifuged at $14,000 \times g$ for $5 \mathrm{~min}$. 
The supernatant was collected, and the soluble protein concentration determined spectrophotometrically. After three freeze-thaw cycles over three months the soluble protein concentration decreased from 48 to $10 \mu \mathrm{M}$ for ZnT8cW and from 57 to $32 \mu \mathrm{M}$ for ZnT8cR (Figure 1). Unless the slightly different initial protein concentration has a strong stabilizing effect, the loss of soluble protein (79 vs. $44 \%$ ) indicates that the $\mathrm{ZnT} 8 \mathrm{cR}$ variant is more stable, consistent with the higher thermostability of this variant [21].

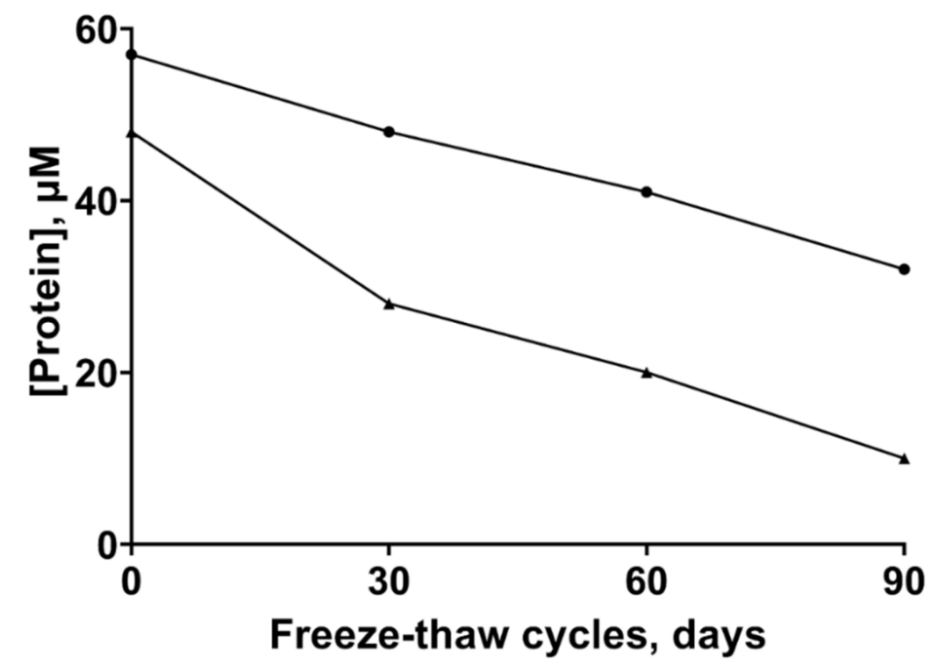

Figure 1. ZnT8c protein stability. Both $\mathrm{ZnT} 8 \mathrm{cR}$ (circles) and $\mathrm{ZnT} 8 \mathrm{cW}$ (triangles) were stored at $-20{ }^{\circ} \mathrm{C}$ in $50 \mathrm{mM}$ TRIS/ $\mathrm{HCl}, \mathrm{pH} 8,500 \mathrm{mM} \mathrm{NaCl}, 300 \mathrm{mM}$ imidazole, $2 \mathrm{mM}$ DTT (dithiothreitol), $100 \mathrm{mM}$ sucrose with $50 \%(v / v)$ glycerol. After each of three freeze-thaw cycles the concentration of soluble protein was determined spectrophotometrically.

\subsection{Electronic Absorption Spectra}

The UV absorption spectra of apo-ZnT8cR or apo-ZnT8cW—defined as no added metal following purification [21] — showed a broad peak at approximately $320 \mathrm{~nm}$, in addition to the typical peaks contributed by aromatic residues at $275-290 \mathrm{~nm}$ (Figure 2). The absorbance at $320 \mathrm{~nm}$ indicates bound nickel. Addition of up to two molar equivalents of $\mathrm{Ni}^{2+}$ to the apo-proteins did not affect the peak at $320 \mathrm{~nm}$. However, upon addition of $\mathrm{ZnCl}_{2}$, the peak at $320 \mathrm{~nm}$ was lost (Figure 2), indicating that the spectroscopically silent $\mathrm{Zn}^{2+}$ displaces the $\mathrm{Ni}^{2+}$.

\subsection{Inductively Coupled Plasma-Mass Spectrometry (ICP-MS) and Total Reflection X-ray Fluorescence (TXRF) Metal Analyses}

The unexpected presence of nickel bound to both ZnT8c variants as indicated by the UV absorbance led us to perform further metal analyses of the proteins. Both apo-variants were purified as previously [21], diluted to $10 \mu \mathrm{M}$ and incubated with 0-10 molar equivalents of $\mathrm{ZnCl}_{2}$. Following gel filtration to remove excess $\mathrm{Zn}^{2+}$, the zinc and nickel content of the proteins was measured using ICP-MS (Tables 1 and 2). Following gel filtration, the protein concentration of both variants was $2 \mu \mathrm{M}$ as measured spectrophotometrically. The two apo-ZnT8c variants, with no additional metal added, contained $0.15-0.19$ total $\mathrm{Zn}^{2+}$ and $\mathrm{Ni}^{2+}$ ions per monomer $(\mathrm{n}=3$; total metal content in Tables 1 and 2 divided by $2 \mu \mathrm{M}$ protein). Over $80 \%$ of this residually bound metal was contributed by $\mathrm{Ni}^{2+}$. Addition of an excess of $\mathrm{Zn}^{2+}$ displaced the bound nickel and the zinc binding capacity was three zinc ions per monomer for both ZnT8c variants, in agreement with our previous zinc stoichiometry data [21]. 


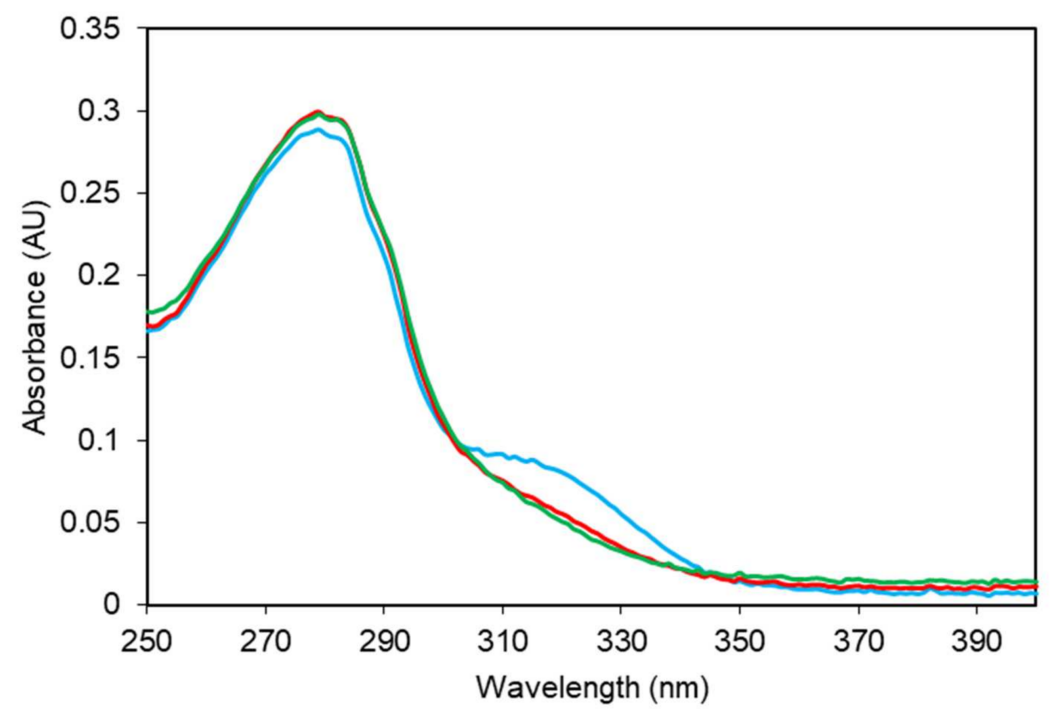

(A)

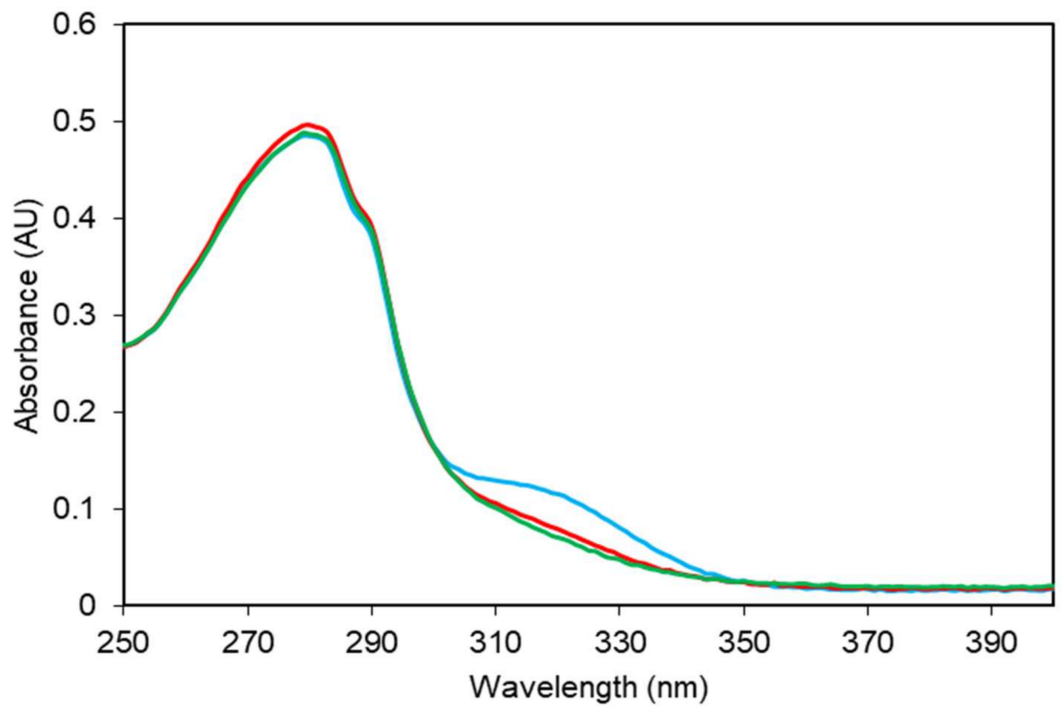

(B)

Figure 2. ZnT8c UV absorbance changes with addition of zinc. Representative $(n=3)$ UV absorbance spectra of $35 \mu \mathrm{M}$ of $\mathrm{ZnT} 8 \mathrm{cR}(\mathbf{A})$ and $\mathrm{ZnT} 8 \mathrm{cW}(\mathbf{B})$ in the absence of $\mathrm{Zn}^{2+}$ (blue), and with one (red) and two (green) molar equivalents of $\mathrm{Zn}^{2+}$, demonstrating that addition of $\mathrm{Zn}^{2+}$ ablates a broad peak at approximately $320 \mathrm{~nm}$ from both apo-ZnT8c variants. Spectra are buffer- and dilution-corrected.

Table 1. Metal analysis (inductively coupled plasma-mass spectrometry (ICP-MS) of zinc and nickel content of $2 \mu \mathrm{M}$ monomeric ZnT8cR after gel filtration following incubation with 0-10 molar equivalents of $\mathrm{Zn}^{2+}(\mathrm{n}=3)$.

\begin{tabular}{ccccc}
\hline \multirow{2}{*}{$\begin{array}{c}\text { Mol. Equiv. Zn } \\
\text { Added }\end{array}$} & Zn $(\mu \mathbf{M})$ & ZnT8cR & Total Metal $(\mu \mathbf{M})$ & Metal:Monomer \\
\cline { 2 - 4 } & $0.03 \pm 0.02$ & $0.26 \pm 0.03$ & 0.29 & 0.15 \\
1 & $2.80 \pm 0.07$ & $0.28 \pm 0.01$ & 3.03 & 1.52 \\
2 & $5.28 \pm 0.39$ & $0.24 \pm 0.02$ & 5.52 & 2.76 \\
4 & $6.65 \pm 0.09$ & $0.12 \pm 0.01$ & 6.77 & 3.39 \\
10 & $5.99 \pm 0.30$ & $0.01 \pm 0.01$ & 6.00 & 3.00 \\
\hline
\end{tabular}


Table 2. Metal analysis (ICP-MS) of zinc and nickel content of $2 \mu \mathrm{M}$ monomeric ZnT8cW after gel filtration following incubation with 0-10 molar equivalents of $\mathrm{Zn}^{2+}(\mathrm{n}=3)$.

\begin{tabular}{ccccc}
\hline \multirow{2}{*}{$\begin{array}{c}\text { Mol. Equiv. Zn } \\
\text { Added }\end{array}$} & Zn $(\mu \mathbf{M})$ & ZnT8cW & Total Metal $(\mu \mathbf{M})$ & Metal:Monomer \\
\cline { 2 - 4 } & $0.04 \pm 0.02$ & $0.33 \pm 0.01$ & 0.37 & 0.19 \\
1 & $2.48 \pm 0.15$ & $0.28 \pm 0.02$ & 2.76 & 1.38 \\
2 & $5.06 \pm 0.21$ & $0.24 \pm 0.02$ & 5.30 & 2.65 \\
4 & $6.51 \pm 0.38$ & $0.12 \pm 0.01$ & 6.63 & 3.32 \\
10 & $6.23 \pm 0.25$ & $0.08 \pm 0.01$ & 6.31 & 3.16 \\
\hline
\end{tabular}

To determine the reason for the higher-than-expected amount of residual nickel bound to the proteins, the source of nickel in the initial preparation was traced to the purification buffers. The buffer preparation protocol was subsequently altered and routine checks performed to control the residual nickel content. Following these changes, total reflection X-ray fluorescence TXRF analyses were performed to determine the protein $\mathrm{Ni}$ and $\mathrm{Zn}$ content (Table 3). We then compared the results obtained by the two different methods of analysis by calculating the metal stoichiometry of the ZnT8c proteins following the change in buffer preparation (with no metal added to the protein solutions during or following purification). Using inductively coupled plasma-mass spectrometry (ICP-MS) analysis, the calculated stoichiometries (metal:protein per monomer) were $0.5 \pm 0.05: 1$ nickel and $0.1 \pm$ 0.06:1 zinc per monomer for ZnT8cW; and $0.6 \pm 0.1: 1$ nickel and $0.2 \pm 0.1: 1$ zinc for ZnT8cR. TXRF analysis indicated that the stoichiometries for ZnT8cW were $0.2 \pm 0.1: 1$ nickel and $0.1 \pm 0.1: 1$ zinc per monomer, while ZnT8cR contained $0.3 \pm 0.1: 1$ nickel and $0.2 \pm 0.1: 1$ zinc per monomer (Table 3 ).

Table 3. Metal stoichiometries of ZnT8 variants from total reflection X-ray fluorescence (TXRF and ICP-MS metal analyses following new buffer preparation protocol.

\begin{tabular}{ccccc}
\hline & \multicolumn{2}{c}{ TXRF } & \multicolumn{2}{c}{ ICP-MS } \\
\cline { 2 - 5 } & Ni:Monomer & Zn:Monomer & Ni:Monomer & Zn:Monomer \\
\hline ZnT8cW & $0.2 \pm 0.1$ & $0.1 \pm 0.1$ & $0.5 \pm 0.05$ & $0.1 \pm 0.06$ \\
ZnT8cR & $0.3 \pm 0.1$ & $0.2 \pm 0.1$ & $0.6 \pm 0.10$ & $0.2 \pm 0.10$ \\
\hline
\end{tabular}

The results for zinc were the same with both methods. ICP-MS showed a slightly higher nickel content of the proteins compared to the TXRF analysis. Importantly, the R-variant showed a consistently higher metal concentration, indicating a slightly higher affinity for both metal ions. After establishing the intrinsic metal stoichiometries of the purified proteins, the next issue to be addressed was the binding stoichiometry when nickel ions are added. The stoichiometry was previously established for zinc and confirmed here in Tables 1 and 2 when also accounting for the nickel initially present in the proteins.

\subsection{Thiol Assay}

Since our previous experiments implicated the involvement of the cysteines at the C-terminus in metal binding, we employed the 5,5'-dithio-bis-(2-nitrobenzoic acid) (DTNB) assay to quantify the free sulfhydryls of both ZnT8c proteins [21]. Alkylation of the sulfhydryls with iodoacetamide was confirmed by measuring only $0.2-0.3$ free sulfhydryls per monomer in the protein with DTNB (Table 4). The experiment determines three cysteines in the protein and demonstrates that no cystines are present, in agreement with three cysteines in the sequence of the protein. These cysteines can be blocked by either alkylation or oxidation (Table 4). 
Table 4. Assaying the sulfhydryls in ZnT8c variants with 5,5'-dithio-bis-(2-nitrobenzoic acid) (DTNB). (A) Free sulfhydryls (thiols) per ZnT8c monomers; (B) Free sulfhydryls (thiols) per ZnT8c monomers after incubating proteins with $15 \mathrm{mM}$ iodoacetamide; (C) Free sulfhydryls (thiols) per ZnT8c monomers after incubating proteins with 15 mM hydrogen peroxide. The experiments were performed in triplicate.

\begin{tabular}{cccccc}
\hline & Variant & $\mathbf{A}_{\mathbf{4 1 2}}$ & TNB, $\boldsymbol{\mu M}$ & ZnT8c, $\boldsymbol{\mu M}$ & Free Thiol/Monomer \\
\hline \multirow{2}{*}{ A } & ZnT8cR & $0.989 \pm 0.01$ & $5.59 \pm 0.01$ & $2 \pm 0.001$ & $2.79 \pm 0.02$ \\
& ZnT8cW & $0.960 \pm 0.01$ & $5.42 \pm 0.01$ & $2 \pm 0.001$ & $2.71 \pm 0.01$ \\
\hline \multirow{2}{*}{ B } & ZnT8cR & $0.500 \pm 0.005$ & $0.62 \pm 0.02$ & $2 \pm 0.005$ & $0.31 \pm 0.02$ \\
& ZnT8cW & $0.512 \pm 0.002$ & $0.63 \pm 0.01$ & $2 \pm 0.002$ & $0.31 \pm 0.04$ \\
\hline \multirow{2}{*}{ C } & ZnT8cR & $0.450 \pm 0.003$ & $0.550 \pm 0.005$ & $2 \pm 0.005$ & $0.27 \pm 0.04$ \\
& ZnT8cW & $0.420 \pm 0.002$ & $0.520 \pm 0.008$ & $2 \pm 0.003$ & $0.26 \pm 0.05$ \\
\hline
\end{tabular}

TNB: 2-nitro-5-thiobenzoate.

\subsection{Determination of the ZnT8c Ni(II) Complex Stoichiometry with Fluorescent (Fluozin-3) and} Colorimetric (Zincon) Indicators

The affinities of the proteins' binding sites for $\mathrm{Ni}(\mathrm{II})$ ions relative to chelating agents were estimated by competition of ZnT8c with FluoZin-3 or Zincon. Both agents are routinely used to measure $\mathrm{Zn}$ (II) ions but they also can be used to measure Ni(II) ions. The reported affinities of FluoZin-3 for nickel and zinc are: FluoZin-3/ Ni ${ }^{2+} 2.85 \pm 0.03 \mathrm{nM}[28]$, FluoZin-3/ $\mathrm{Zn}^{2+} 9.1 \pm 0.4 \mathrm{nM}$ [29]. $\mathrm{Zn}^{2+}$ binds Zincon with a dissociation constant of $7 \pm 1 \mu \mathrm{M}$, which is weaker than that for $\mathrm{Ni}^{2+}$ ions $[30,31]$.

To investigate the stoichiometry of nickel binding to $\mathrm{ZnT} 8 \mathrm{c}$ in competition with FluoZin-3 or Zincon, two independent methods were used: a classical approach (Job's method) and a relatively new one (the complementary approach). Zincon or FluoZin-3 was mixed with nickel ions in the buffer. Addition of Ni(II) ions to Zincon at pH 6.0, 7.0, and 8.0 resulted in shifts of the absorbance maxima from $488 \mathrm{~nm}$ (Zincon alone) to $653 \mathrm{~nm}$ (Zincon-nickel complex). Fluorescence of FluoZin-3 $(\lambda \mathrm{ex}=480 \mathrm{~nm}$ and $\lambda \mathrm{em}=520 \mathrm{~nm})$ showed a small shift in the position of the excitation wavelength $(\lambda \mathrm{ex}=490 \mathrm{~nm})$ at all $\mathrm{pH}$ values examined, demonstrating the $\mathrm{Ni}(\mathrm{II})$ complex formation. Under all tested conditions a $1: 1 \pm 0.1$ stoichiometry was detected in the Zincon- $\mathrm{Ni}^{2+}$ or the FluoZin-3-Ni ${ }^{2+}$ system (Figure 3).

A

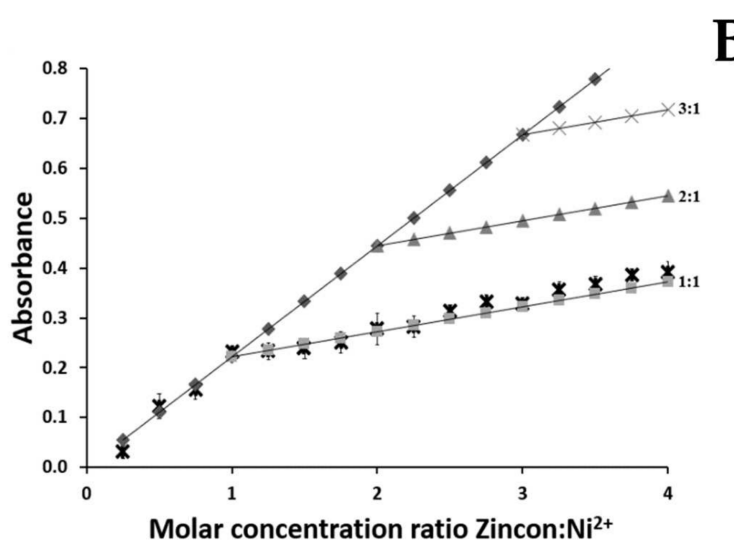

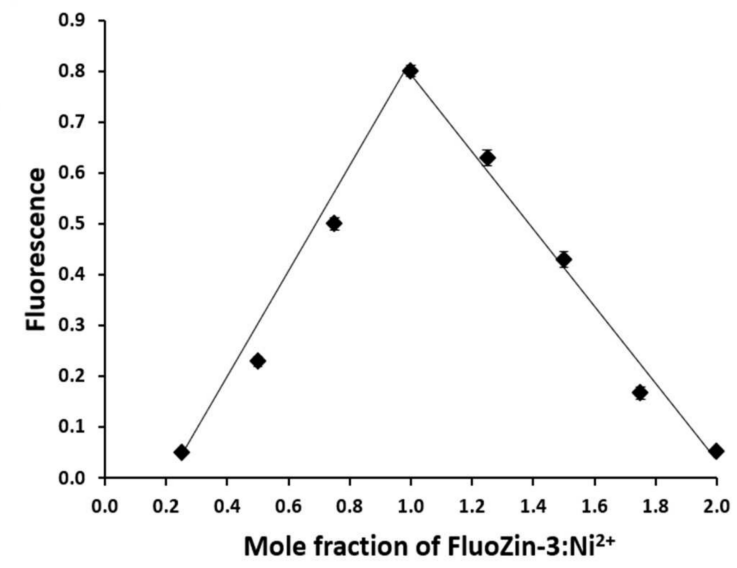

Figure 3. Assessment of the Zincon-Ni(II) and FluoZin-3-Ni(II) complex stoichiometry at pH 7.0. (A) Complementary Approach. The molar concentration of $\mathrm{Ni}(\mathrm{II})$ ions was kept constant at $25 \mu \mathrm{M}$ and the total molar concentration of Zincon was continuously varied from 6 to $100 \mu \mathrm{M}$. The line with the grey diamonds corresponds to the absorbance of the complex formed after an excess of nickel was added. The other lines represent the theoretical absorbances expected if the stoichiometries were 1:1 (squares), 2:1 (triangles) or 3:1 (crosses). The comparison between the measured absorbance (black crosses) with the theoretical lines establishes a stoichiometry of 1:1. (B) Job's method. The ratios refer to chelating agent/nickel. The total molar concentration of FluoZin-3 and Ni(II) was $100 \mu \mathrm{M}$. The lines converge on a molar ratio of 1:1. The assessment was performed with three independent stock solutions. 
ICP-MS analyses showed that both ZnT8c proteins contained $0.50 \pm 0.05$ (ZnT8cW) and $0.60 \pm 0.1$ (ZnT8cR) nickel per monomer following purification (Tables 3 and 5). Each ZnT8c variant $(5 \mu \mathrm{M})$ then was incubated with $\mathrm{Ni}^{2+}$ (from 0 to $100 \mu \mathrm{M}$ ) with or without $15 \mathrm{mM}$ iodoacetamide and underwent gel filtration to remove excess $\mathrm{Ni}^{2+}$. Stoichiometry calculations are based on the increasing fluorescence/absorbance when $10 \mu \mathrm{M} \mathrm{Ni}^{2+}$ was added in competition with $5 \mu \mathrm{M}$ of protein (Figure 4). ICP-MS analysis also was performed after adding $10 \mu \mathrm{M} \mathrm{Ni}^{2+}$ in the presence and absence of iodoacetamide and the stoichiometries calculated (Table 5).

Table 5. Metal stoichiometries of ZnT8c variants from Ni(II) binding data.

\begin{tabular}{ccccccc}
\hline & $\begin{array}{c}\text { Proteins as Isolated } \\
\text { (ICP-MS) }\end{array}$ & $\begin{array}{c}\text { Proteins with Free } \\
\text { Cysteines } \\
\text { (ICP-MS) }\end{array}$ & $\begin{array}{c}\text { Proteins with } \\
\text { Blocked Cysteines } \\
\text { (ICP-MS) }\end{array}$ & $\begin{array}{c}\text { Proteins with Free } \\
\text { Cysteines } \\
\text { (Competition Assay) }\end{array}$ & $\begin{array}{c}\text { Proteins with Blocked } \\
\text { Cysteines } \\
\text { (Competition Assay) }\end{array}$ \\
\cline { 2 - 6 } & Nickel:Monomer & Nickel:Monomer & Nickel:Monomer & Nickel:Monomer & Nickel:Monomer \\
\hline ZnT8cW & $0.50 \pm 0.05$ & $2.00 \pm 0.01$ & $1.26 \pm 0.05$ & $1.98 \pm 0.02$ & $1.25 \pm 0.07$ \\
ZnT8cR & $0.60 \pm 0.01$ & $1.97 \pm 0.01$ & $0.97 \pm 0.03$ & $2.00 \pm 0.03$ & $1.00 \pm 0.02$ \\
\hline
\end{tabular}

A

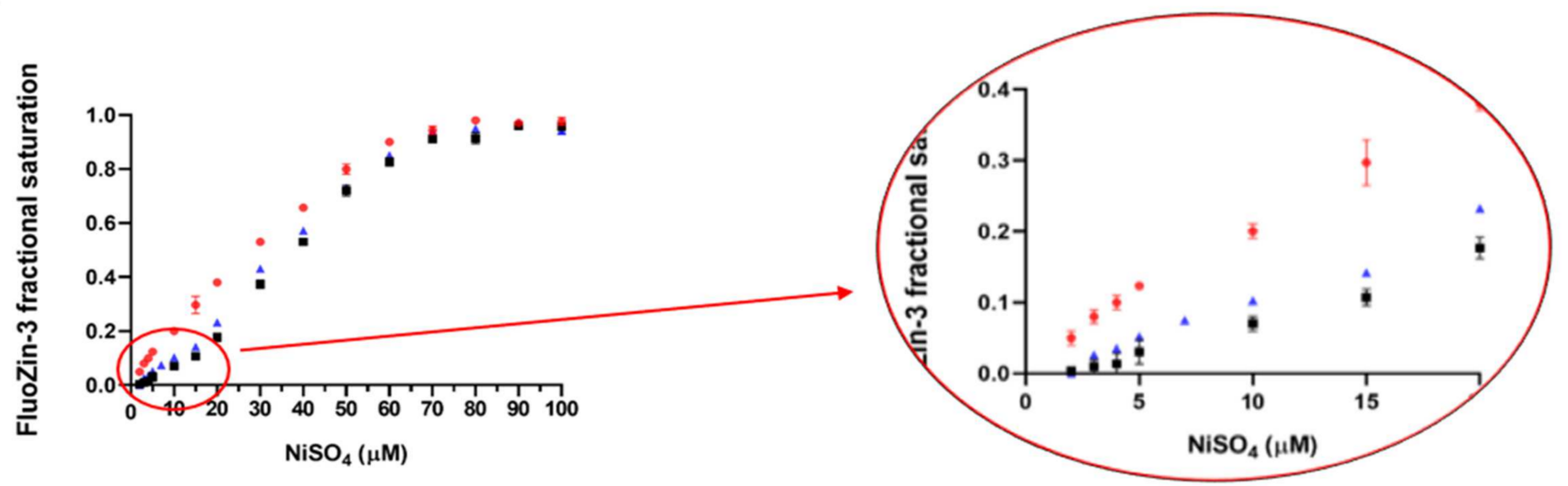

B
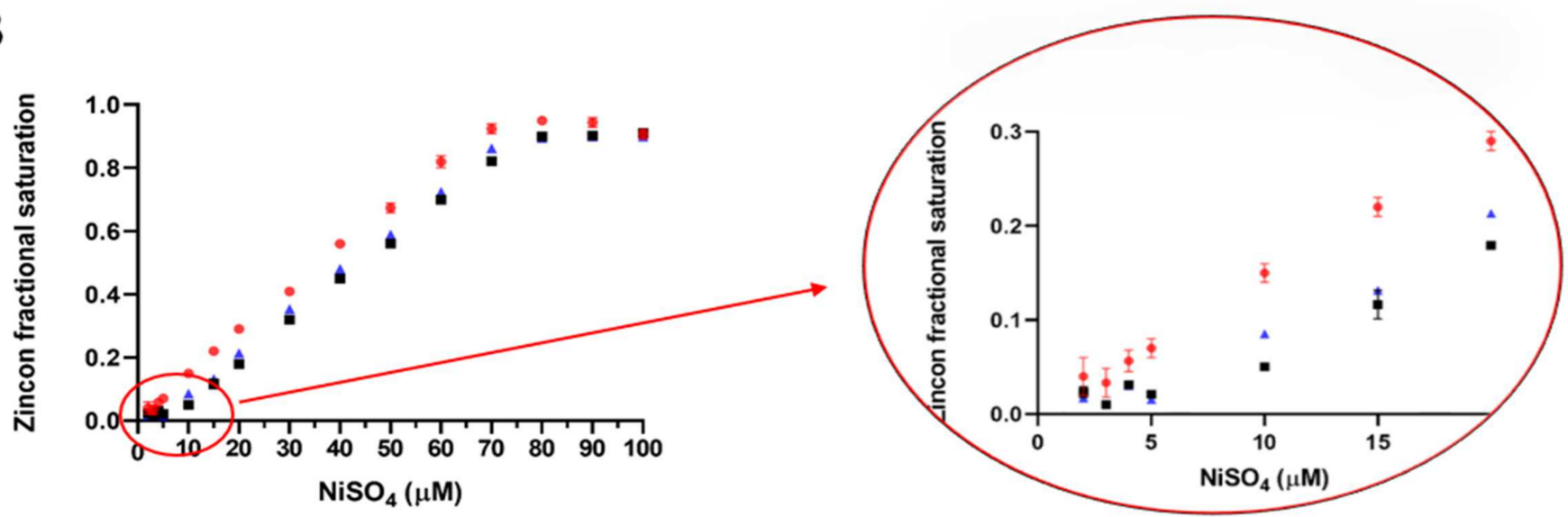

Figure 4. Cont. 
C
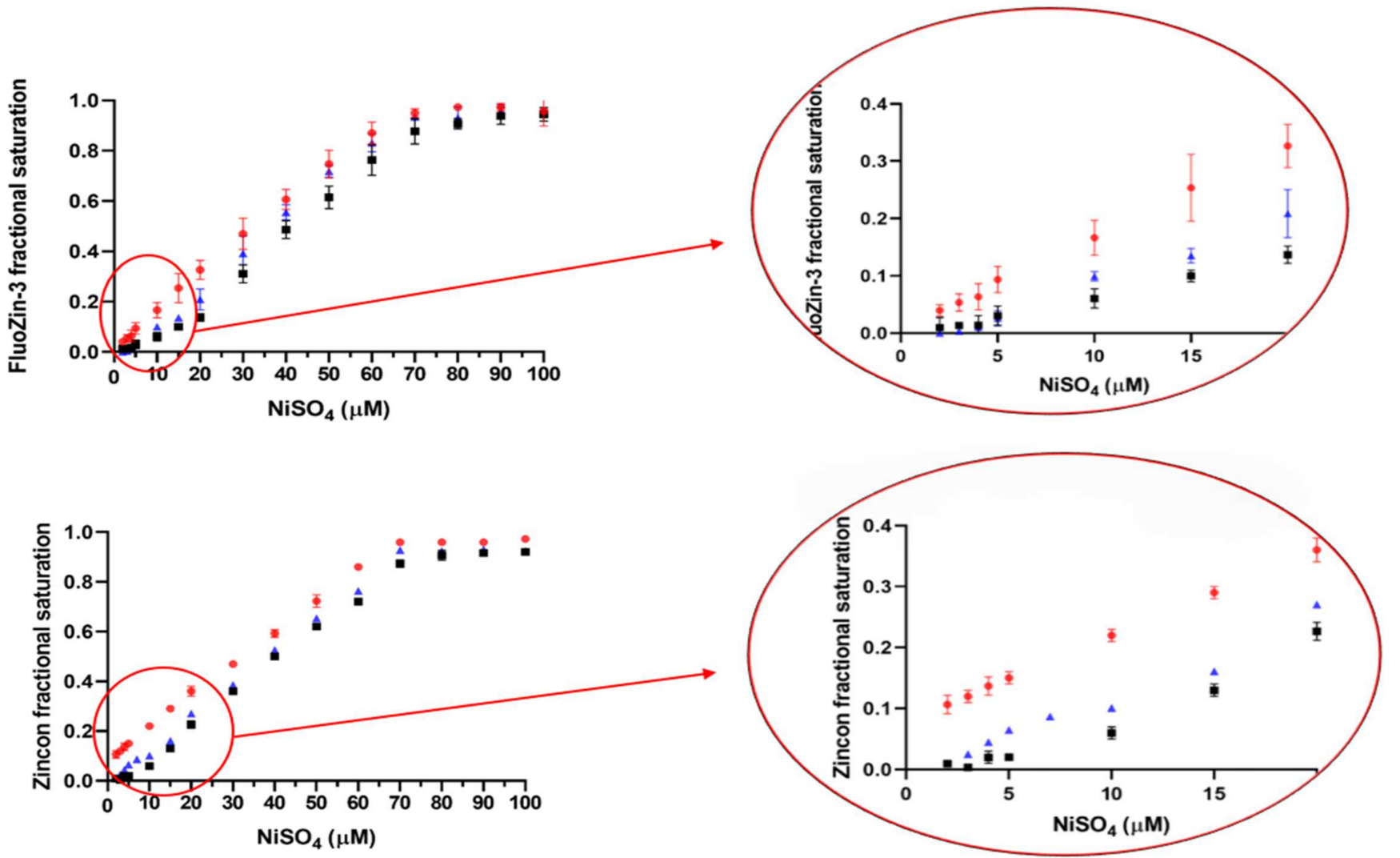

Figure 4. Nickel affinity of the two ZnT8 C-terminal domain (CTD) variants before and after alkylation. ZnT8cW. Nickel binding in competition with FluoZin-3 (A) and Zincon (B). Measuring fluorescence at $515 \mathrm{~nm}$ and absorbance at $653 \mathrm{~nm}$, $70 \mu \mathrm{M} \mathrm{NiSO}_{4}$ saturates $70 \mu \mathrm{M}$ FluoZin-3/Zincon in $50 \mathrm{mM}$ HEPES (4-(2-hydroxymethyl)-1-piperazineethanesulfonic acid), $300 \mathrm{mM} \mathrm{NaCl}, 100 \mathrm{mM}$ sucrose, $\mathrm{pH} 8$ in agreement with the stoichiometry of the complex (red circles). In competition with $5 \mu \mathrm{M} \mathrm{ZnT} 8 \mathrm{cW}$, no signals at $515 \mathrm{~nm}$ or $653 \mathrm{~nm}$ are detected until $10 \mu \mathrm{M} \mathrm{NiSO}_{4}$ is added, revealing two high-affinity nickel binding sites in ZnT8cW which outcompete FluoZin-3/Zincon (black squares). When ZnT8cW is incubated with iodoacetamide for $1 \mathrm{~h}$ prior to the FluoZin-3/Zincon competition assay, only $5 \mu \mathrm{M} \mathrm{NiSO}_{4}$ is required to elicit the initial signals at 515 and $653 \mathrm{~nm}$ and the stoichiometry decreases to 1 (blue triangles). ZnT8cR. Nickel binding in competition with FluoZin-3 (C) and Zincon (D). $\mathrm{NiSO}_{4}$ titration of FluoZin-3/Zincon alone in HEPES buffer (red circles), in competition with $\mathrm{ZnT} 8 \mathrm{cR}$ (black squares), and in competition with ZnT8cR modified with iodoacetamide (blue triangles), demonstrates that $\mathrm{ZnT} 8 \mathrm{cR}$ also contains two high affinity nickel binding sites and that one binding site is blocked by alkylation.

The competition assays and ICP-MS analyses demonstrate that both ZnT8c proteins bind two $\mathrm{Ni}^{2+}$ ions per monomer in high affinity sites (Figure 4 and Table 5). Once the cysteines are blocked, the nickel:protein stoichiometry decreases from 2:1 to 1:1. The data from both direct metal analyses and competition assays therefore show that the cysteines at the C-terminus are one of the two binding sites for nickel.

\subsection{Circular Dichroism (CD) Spectroscopy}

The spectra in the region 260-320 nm arise from the aromatic amino acids. Each of the amino acids has a characteristic wavelength profile. ZnT8cR contains four Tyr, two Phe, and one Trp residue; ZnT8cW contains an extra Trp. Subtraction of the apo-ZnT8cR near-UV $\mathrm{CD}$ spectrum from that of apo-ZnT8cW reveals a single negative peak at approximately $285 \mathrm{~nm}$ (Figure 5), within the expected range for Trp residues. The differences in the near UV CD of the two proteins demonstrate that the environment of the extra Trp in ZnT8cW can be investigated by difference spectroscopy. Since we observed light absorption of the isolated proteins above $300 \mathrm{~nm}$, we suspected that the absorbance is indicative of bound $\mathrm{Ni}$ (II) ions, which can be used as a spectroscopic probe of the zinc-binding sites in the CTD. To gain more insight into the coordination, we extended the CD spectra to the visible 
region of the spectrum for both species. A positive CD band at $312 \mathrm{~nm}$ and a negative one at $484 \mathrm{~nm}$ were observed. The latter is also indicative of the presence of nickel and becomes more pronounced when the protein's binding sites are saturated by adding $0.1 \mathrm{mM} \mathrm{Ni}^{2+}$. A small difference in the CD spectra of the two variants was observed (Figure 6) and the negative $C D$ band at $484 \mathrm{~nm}$ of $\mathrm{ZnT} 8 \mathrm{cW}+0.1 \mathrm{mM}$ of $\mathrm{Ni}^{2+}$ was observed as well. Moreover, only the CD spectrum of ZnT8cR $+0.1 \mathrm{mM}^{\circ} \mathrm{Ni}^{2+}$ shows a positive band around $550 \mathrm{~nm}$ and a negative band at around $650 \mathrm{~nm}$. To determine if the $\mathrm{ZnT} 8 \mathrm{c} \mathrm{Ni}{ }^{2+}$ binding site has free coordinating ligands, $\mathrm{NaN}_{3}$ was added to a final concentration of $0.3 \mathrm{mM}$. This experiment is based on the expectation that, if there were a water or non-protein ligand bound to ZnT8c, the displacement of such a ligand by binding to a nitrogen donor from the azide would provoke a change in the CD spectrum, as documented for azide binding to $\mathrm{Ni}^{2+}$ in the active site of horse liver alcohol dehydrogenase [32]. The spectra did not change substantially, indicating that the $\mathrm{Ni}(\mathrm{II})$ site(s) were coordinatively saturated by ligand donors from amino acids and not accessible. These experiments reveal differences in the $\mathrm{Ni}$ (II) binding sites in the two variants and establish that $\mathrm{Ni}$ (II) ions can be used to examine structural differences between the two proteins.

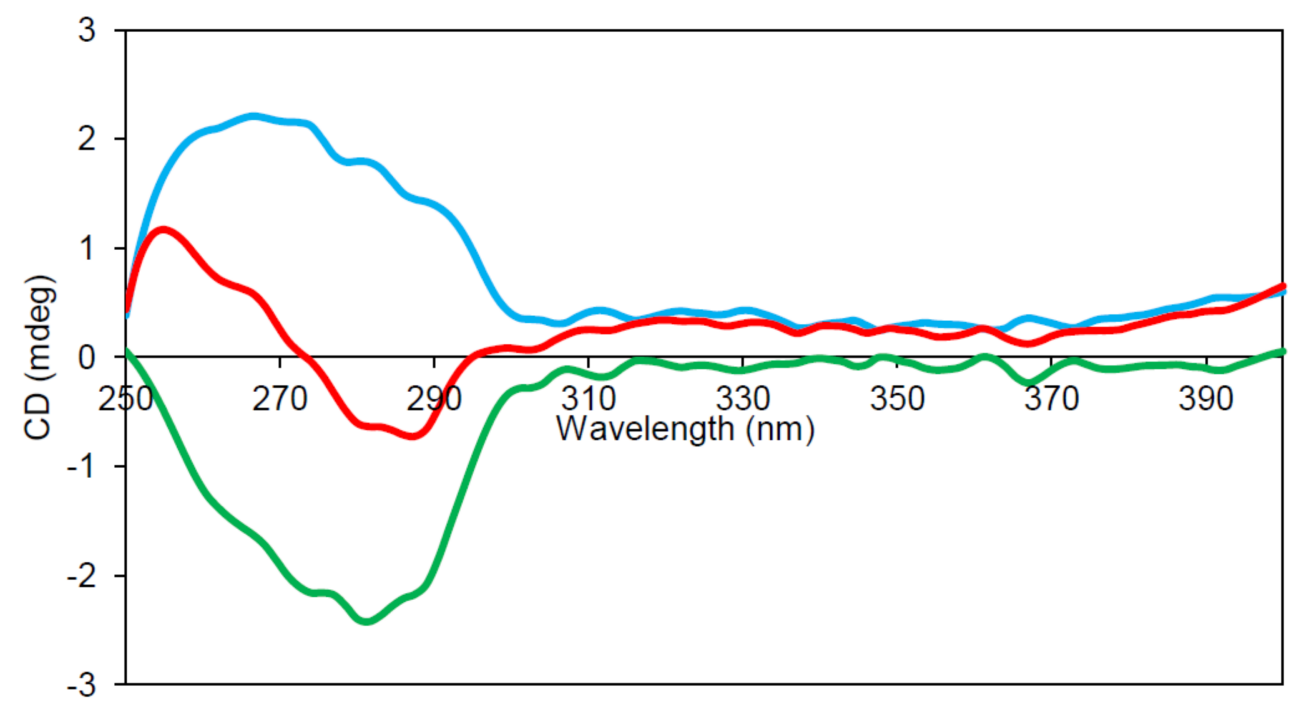

Figure 5. Near-UV circular dichroism (CD) of the two ZnT8c variants. Representative $(n=3)$ near-UV CD spectra of $0.4 \mathrm{mg} / \mathrm{mL}$ ZnT8cR (blue) and ZnT8cW (green) in $50 \mathrm{mM}$ Tris, $300 \mathrm{mM} \mathrm{NaCl}, 100 \mathrm{mM}$ sucrose, $100 \mu \mathrm{M}$ Tris(2-carboxyethyl)phosphine hydrochloride (TCEP), pH 8. Subtracting the ZnT8cR spectrum from that of $\mathrm{ZnT} 8 \mathrm{cW}$ provides the expected CD of W325 in the protein alone (red).

\subsection{Potentiometric Characterization of Zinc Binding to N-Terminal and C-Terminal Peptides of ZnT8}

As the $\mathrm{N}$-terminus, which is part of the transmembrane domain, has a $\mathrm{HCH}$ metalbinding motif, we synthesised an N-terminal fragment of ZnT8 (Ac-MYHCHSGS-NH $\mathrm{N}_{2}$ ) and tested its ability to bind zinc ions. Though the peptide contains a tyrosine and is thus amenable to fluorescence spectroscopy, the most reliable data were obtained using the potentiometry method. The protonation and stability constants for the peptide and the complex with Zn(II) are given in Table 6. 


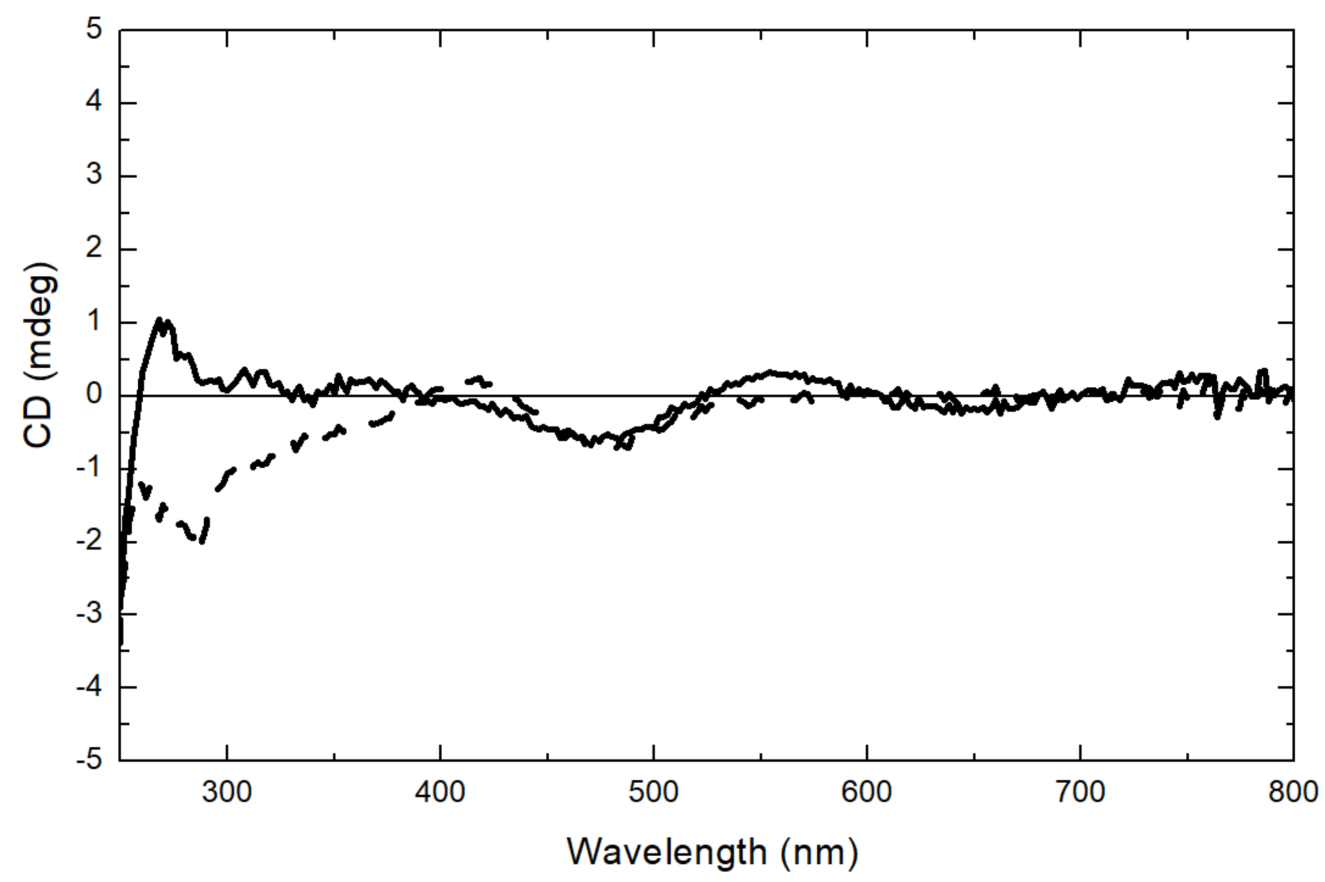

Figure 6. CD spectra of $\mathrm{ZnT} 8 \mathrm{c}$ with $\mathrm{Ni}^{2+}$ excess. $\mathrm{ZnT} 8 \mathrm{cR}+0.1 \mathrm{mM} \mathrm{NiSO}_{4}$ (black line) and $\mathrm{ZnT} 8 \mathrm{cW}$ + $0.1 \mathrm{mM}$ of $\mathrm{NiSO}_{4}$ (dotted line) in $50 \mathrm{mM}$ Tris, $300 \mathrm{mM} \mathrm{NaCl}, 100 \mathrm{mM}$ sucrose, $100 \mu \mathrm{M} \mathrm{TCEP}, \mathrm{pH}$ $8,10 \mathrm{~mm}$ pathlength. The concentrations of the ZnT8c proteins were $35 \mu \mathrm{M}$. Corrected for buffer baseline.

Table 6. Protonation constants $(\log \beta)$ for the ZnT8 8-residue N-terminal peptide and stability constants $(\log \beta)$ for its zinc(II)-peptide complexes, ionic strength $0.1 \mathrm{M}\left(\mathrm{KNO}_{3}\right), 25^{\circ} \mathrm{C}$. The protonated residues in each species are predicted based on amino acid $\mathrm{p} K_{\mathrm{a}}$ values.

\begin{tabular}{cccc}
\hline $\mathbf{Z n} \boldsymbol{p}) \mathbf{L} \boldsymbol{q} \mathbf{H} \boldsymbol{r}$ & $\log \boldsymbol{\operatorname { l o g }} \boldsymbol{K}$ & Predicted Protonated Residue \\
\hline $\mathrm{LH}$ & $10.58 \pm 0.02$ & 10.58 & Tyrosine side chain \\
$\mathrm{LH}_{2}$ & $19.84 \pm 0.02$ & 9.27 & Cysteine sulfhydryl \\
$\mathrm{LH}_{3}$ & $26.89 \pm 0.02$ & 7.05 & Histidine side chain \\
$\mathrm{LH}_{4}$ & $32.71 \pm 0.02$ & 5.82 & Histidine side chain \\
$\mathrm{ZnLH}$ & $18.85 \pm 0.02$ & & \\
$\mathrm{ZnL}$ & $9.58 \pm 0.02$ & & \\
\hline
\end{tabular}

Remarkably, the peptide $\mathrm{p} K_{\mathrm{a}}$ value for one of the histidines is lower than expected and the $\mathrm{p} K_{\mathrm{a}}$ of the tyrosine is higher than 10 . These findings suggest additional interactions between these two residues. Zn(II) binds to the ZnT8 N-terminal fragment through the Cys and at least one of the His residues. The conditional dissociation constant value of $K_{d}=0.56$ $\pm 0.03 \mu \mathrm{M}$ (pH 7.4) is too weak to indicate a significant biological role of the N-terminal peptide alone. The calculation was made using the competitivity index (CI) approach based on the potentiometric stability constants [33]. In view of our previous investigations showing the participation of the C-terminal cysteines in zinc coordination [21] and the observation here that the cysteines also interact with $\mathrm{Ni}(\mathrm{II})$ ions, we also synthesized an 11-residue C-terminal peptide of human ZnT8, sequence Ac-PDCLFCEDPCD (denoted 'L' for ligand in Figure 7 and Tables 7 and 8), verified its mass using mass spectrometry, and characterized its protonation and zinc binding. Visible spectroscopy measurements indicated that concentrations of peptide greater than $0.2 \mathrm{mM}$ were insoluble in the $\mathrm{HNO}_{3} / \mathrm{KNO}_{3}$ reaction solution. Therefore, $180 \mu \mathrm{M}$ peptide was prepared in $7.5 \mathrm{~mL}$ of $0.4 \mathrm{mM} \mathrm{HNO}_{3} / 99.6 \mathrm{mM}$ $\mathrm{KNO}_{3}$ solution. The protonation constants from potentiometric titrations of the peptide with $0.1 \mathrm{M} \mathrm{NaOH}$ (carbon dioxide free) indicated that the major protonated species of the C-terminal apo-peptide is $\mathrm{LH}_{4}$ at pH 7.4 (Table 7; Figure 7A). Comparing the modelled log $K$ protonation constants to a physiological $\mathrm{pH}$ of 7.4 , the first four protonations $\left(\mathrm{LH}-\mathrm{LH}_{4}\right)$ 
occur at a $\mathrm{pH}$ higher than 7.4. According to assignments provided in Table 7, the three cysteine residue thiols $\left(\mathrm{p} K_{\mathrm{a}}=8.9-10.1\right)$ and the $\mathrm{N}$-terminal amine are protonated at $\mathrm{pH}$ 7.4. To determine the zinc affinity of the peptide, separate peptide samples were incubated with $0.5,0.65,0.8$ and 0.9 molar equivalents of $\mathrm{Zn}^{2+}$, and titrated with $0.1 \mathrm{M} \mathrm{NaOH}$ as for the apo-peptide. Modeling of these data yielded stability constants of the peptide- $\mathrm{Zn}^{2+}$ complex (Table 8). The stability constant of the first peptide ligand ( $\mathrm{ZnL}, \log K 15.98$ ) is much higher than that of the second ligand $\left(\mathrm{ZnL}_{2}, \log K\right.$ 7.35). Therefore, the $\mathrm{ZnL}_{2}$ complex does not form to a significant degree and can be ignored during modeling of the physiological speciation. The zinc-ligand species distribution diagram indicates a mix of $58 \% \mathrm{ZnLH}$ and $42 \% \mathrm{ZnLH}_{2}$ at $\mathrm{pH} 7.4$ (Figure $7 \mathrm{~B}$ ). The effective $\log \mathrm{K}$ of the peptide for $\mathrm{Zn}$ (II) ions can be calculated using the CI approach [33]. The CI calculated for the $\mathrm{Zn} / \mathrm{L}$ system is 8.24 , hence the $K_{\mathrm{d}}$ of the C-terminal 11-residue peptide of $\mathrm{ZnT} 8$ for $\mathrm{Zn}^{2+}$ at $\mathrm{pH}$ 7.4 is $10^{-8.24} \mathrm{M}(5.8 \mathrm{nM})$.

A

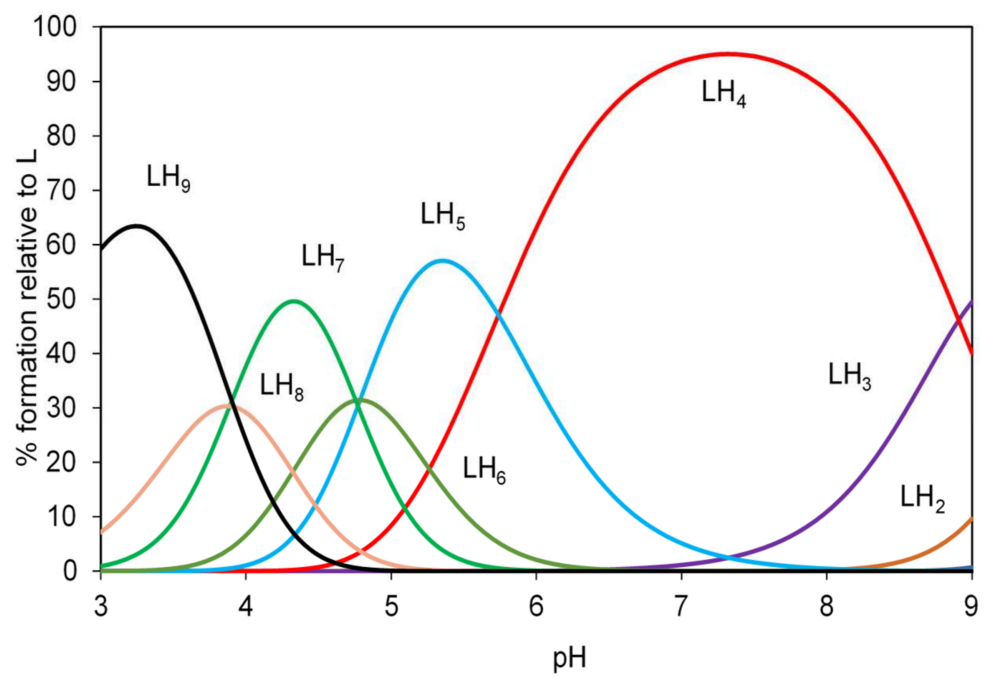

B

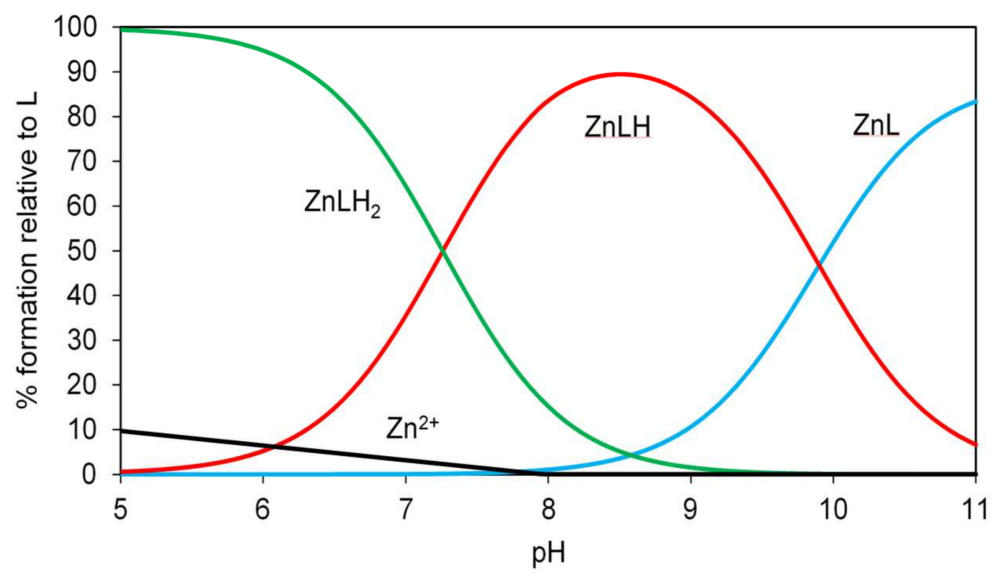

Figure 7. Speciation diagrams for the ZnT8 11-residue C-terminal peptide. (A) Protonation of $180 \mu \mathrm{M}$ peptide (denoted $\mathrm{L}$ ) during titration with $\mathrm{NaOH}$ according to data in Table 6. At pH 7.4 the dominant species is $\mathrm{LH}_{4}$ (red). (B) Modeling of $180 \mu \mathrm{M}$ peptide with $200 \mu \mathrm{M} \mathrm{Zn^{2+ }}$ using the stability constants in Table 8 reveals that at $\mathrm{pH} 7.4$ there is a mix of $58 \% \mathrm{ZnLH}$ (red) and $42 \% \mathrm{ZnLH}_{2}$ (green) relative to the peptide concentration. In both experiments the ionic strength is $0.1 \mathrm{M}$ and the temperature is $25^{\circ} \mathrm{C}$. 
Table 7. Protonation constants $(\log \beta)$ for the ZnT8 11-residue C-terminal peptide, ionic strength $0.1 \mathrm{M}\left(\mathrm{KNO}_{3}\right), 25^{\circ} \mathrm{C}$. The protonated residues in each species are predicted based on amino acid $\mathrm{p} K_{\mathrm{a}}$ values.

\begin{tabular}{cccc}
\hline $\mathbf{L} q \mathbf{H} \boldsymbol{r}$ & $\log \boldsymbol{\beta}$ & $\log \boldsymbol{K}$ & Predicted Protonated Residue \\
\hline $\mathrm{LH}$ & 11.29 & 11.29 & Proline $\alpha$-amino \\
$\mathrm{LH}_{2}$ & 21.43 & 10.14 & Cysteine sulfhydryl \\
$\mathrm{LH}_{3}$ & 31.14 & 9.71 & Cysteine sulfhydryl \\
$\mathrm{LH}_{4}$ & 40.05 & 8.91 & Cysteine sulfhydryl \\
$\mathrm{LH}_{5}$ & 45.79 & 5.74 & Glutamic acid side chain \\
$\mathrm{LH}_{6}$ & 50.57 & 4.78 & Aspartic acid side chain \\
$\mathrm{LH}_{7}$ & 55.33 & 4.76 & Aspartic acid side chain \\
$\mathrm{LH}_{8}$ & 59.22 & 3.89 & Aspartic acid side chain \\
$\mathrm{LH}$ & 63.14 & 3.92 & Aspartic acid $\alpha$-COOH \\
\hline
\end{tabular}

Table 8. Stability constants $(\log \beta)$ for zinc(II)-peptide complexes of the ZnT8 11-residue C-terminal peptide, ionic strength $0.1 \mathrm{M}\left(\mathrm{KNO}_{3}\right), 25^{\circ} \mathrm{C}$.

\begin{tabular}{ccc}
\hline $\mathbf{Z n} \boldsymbol{p} \mathbf{L} \boldsymbol{q} \mathbf{H} \boldsymbol{r}$ & $\log \boldsymbol{\beta}$ & $\log \boldsymbol{K}$ \\
\hline $\mathrm{ZnL}$ & 15.98 & 15.98 \\
$\mathrm{ZnLH}$ & 25.88 & 9.9 \\
$\mathrm{ZnLH}_{2}$ & 33.14 & 7.26 \\
$\mathrm{ZnL}_{2}$ & 23.33 & 7.35 \\
$\mathrm{ZnL}_{2} \mathrm{H}$ & 33.85 & 10.52 \\
$\mathrm{ZnL}_{2} \mathrm{H}_{2}$ & 44.20 & 10.35 \\
$\mathrm{ZnL}_{2} \mathrm{H}_{3}$ & 53.43 & 9.23 \\
$\mathrm{ZnL}_{2} \mathrm{H}_{4}$ & 63.01 & 9.58 \\
\hline
\end{tabular}

\section{Discussion}

The vesicular subfamily of mammalian ZnTs $(\mathrm{ZnT2}-4,8)$ mediates the transport of zinc from the cytosol into functionally critical intracellular secretory granules. While the general architecture of the transporters themselves have been predicted from bacterial homologues for some time, and the $\mathrm{Zn}^{2+} / \mathrm{H}^{+}$antiport transport mechanism described in previous transport assays, answers to several fundamental biochemical issues about these transporters remain elusive. The overarching problem is how these proteins access the tightly controlled cytosolic pool of zinc, most of which is bound to proteins with high affinity. In the bacterial proteins, the CTD acts as an allosteric gatekeeper, activating the transporter upon detection of a cytoplasmic $\mathrm{Zn}$ (II) ion threshold. Our analysis showed that essential residues are missing from the CTD in the mammalian proteins [21]. Therefore, the aim of our work was to answer the general questions of why the mammalian ZnT cytosolic domain binds metal ions, whether it senses zinc ions for export, and if so, at which concentrations, and how selective the binding sites for metal ions are. Specifically, for ZnT8, we are also investigating how the W/R mutation at the apex of the CTD of ZnT8 affects metal transport far away in the transmembrane domain and thus can modulate the risk to developing type 2 diabetes. Two recent cryo-EM structures of full-length human ZnT8 describe its overall structure $[19,20]$. One of the two investigations provides a model at relatively high resolution (3-5 $\AA$ ) and important new information on metal binding [20]. The CTD indeed adopts the ferredoxin-type $\alpha \beta$-fold predicted from CD studies [21]. As we also predicted, the cryo-EM structure revealed that full-length ZnT8 binds two zinc ions in the CTD, the same number as in E. coli YiiP. However, the site location and coordinating residues in the ZnT8 CTD binding sites are partially distinct from those in YiiP. One difference is the participation of two cysteines from the C-terminus of the CTD. Remarkably, the N-terminal domain (NTD) that is present only in the fulllength ZnT8 protein also provides ligands to complement the coordination spheres of both zinc binding sites in the CTD [20]. The NTD contains an HCH motif, in which all three ligands are used in a three-pronged mode of binding. The first binding site in the 
CTD is formed of two histidines (H301 \& 318) and one glutamate (E352) provided by the CTD, and one cysteine (C53) provided by the NTD [20]. This site is analogous to one of the two sites in the CTD of E. coli YiiP, with H301, H318 and E352 being analogous to H232, H248 and D285 in YiiP, as we predicted previously [21]. However, the fourth ligand providing the tetrahedral geometry in YiiP is a water molecule, as opposed to the NTD C53 in ZnT8c (Figure 8) [20]. Therefore, the solvent accessibility of this bound zinc ion is different between the bacterial and human proteins. The ligands providing the second zinc binding site in the CTD of E. coli YiiP are not conserved in mammalian ZnTs [21]. Thus, the second metal binding site in ZnT8c is novel and is formed of two histidines (H52 \& 54) from the NTD which complement the two cysteine ligands (C361 \& 364) from the CTD (Figure 8) [20]. Thus, remarkably, this site is formed entirely from ligands stemming from both termini of the protein. The recent ZnT8 cryo-EM structure at the high resolution therefore verifies our previous and current results showing that the C-terminal cysteine residues in ZnT8c provide a metal binding site [21] and indicate that it is important for the function of the full-length protein. The functional implications of these ZnT8c metal binding sites are vast. The C-terminal cysteines are unique for the vesicular $\mathrm{ZnTs}$, and their absence in the CDF/ZnT plasma membrane transporters in both prokarya and eukarya led to the prediction that non-vesicular ZnTs contain only one metal binding site in their CTD [21]. The vesicular transporters must acquire zinc from an unknown donor in a tightly zinc-buffered cytosol, whereas the exporters remove an excess/surplus of zinc; the novel CTD metal ligands from the C- and N-termini in the vesicular subfamily, as exemplified here by ZnT8, suggest that at least one zinc ion is acquired through the $\mathrm{C}$-terminal cysteines. Instead of a ligand from the other subunit bridging the binuclear metal site, as in the dimer of YiiP, the tripartite N-terminal HCH motif in ZnT8 serves as a brace for linking the two metal sites. Thus far, such a coordination of metal sites is unique in bioinorganic chemistry and it is the first example of zinc/sulfur coordination chemistry in eukaryotic zinc transporter biology.

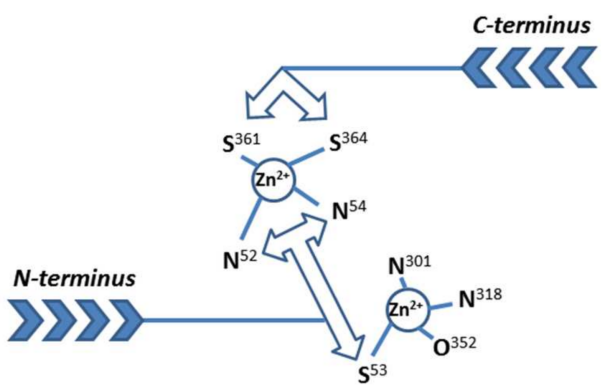

Figure 8. The two $\mathrm{Zn}^{2+}$-binding sites in the cytosolic C-terminal domain (CTD) of human ZnT8. The presentation is based on a recent Cryo-EM structure of the entire protein [20]. One metal ion is bound by two N-donors from histidines (301 \& 318) and one O-donor from glutamate (352). An S-donor from cysteine (53) from the N-terminus (not present in the CTD) complements a tetrahedral binding geometry. The second site is assembled from donors of the C- and N-termini only: Two S-donors from cysteines ( $361 \& 364$ ) from the C-terminus and two N-donors from histidines (52 \& 54) from the $\mathrm{N}$-terminus. The N-terminal tripartite motif with adjacent metal-coordinating amino acid side chains $(\mathrm{HCH})$ "seals off" the metal sites [20]. Both termini have to swing into the site to effect coordination of the second metal ion.

The involvement of cysteine residues in both CTD metal binding sites indicates that zinc binding is dependent on the cellular redox balance. This observation is significant as oxidative stress in pancreatic $\beta$-cells, which is recognised as a fundamental aspect of type 2 diabetes pathology [34], is expected to affect zinc binding to the CTD. Since the CTD binds two metal ions with relatively high affinity in the absence of the TMD with its N-terminus, it is now important to determine the contribution of the $\mathrm{N}$-terminal $\mathrm{HCH}$ motif to affinity and function. It is noteworthy that investigations with a synthetic peptide 
of human $\mathrm{ZnT3}$ bearing the $\mathrm{HCH}$ motif already have shown relatively high affinity zinc binding, a significant preference of zinc over nickel, and has implicated the motif in the function of the vesicular transporters [35]. The rather disordered C-terminal tail of ZnT8 (and by inference that of other vesicular ZnTs) may serve as a swinging arm that acquires zinc through coordination to its three cysteines and then swings over to form the metal site with the other ligands. The single digit nanomolar affinity of the C-terminal peptide for zinc supports such a role. The flexibility of the C-terminal tail and the low sigma value of zinc in the site with the two cysteines from the tail also support such coordination dynamics [20]. "Putting a brace on" with the N-terminal HCH motif would then essentially capture zinc ions in this site. The important feature of such coordination dynamics is that the N-terminus connects to TM1, which together with TM2,4 \&5 is critical for the dynamics of the protein in alternating between the inward and outward conformation for transport [20].

Owing to its filled d-shell, the $\mathrm{Zn}$ (II) ion is spectroscopically silent for many types of spectroscopies. One approach to overcome this experimental challenge is to employ transition metal ions with specific spectroscopic signatures to examine zinc-binding sites in proteins and to gain information about the coordination environments [36]. After noting that $\mathrm{Ni}$ (II) ions bind to the cytosolic domain of the zinc transporter ZnT8 (ZnT8c) during purification, we employed nickel ions to probe the metal-binding properties of the two variants and to gain further insights in the coordination environments of zinc. The ZnT8c variants with $\mathrm{Ni}$ (II) ions bound have different CD spectra, supporting our previous conclusion that the differences in metal binding impart slightly different properties on the protein. The spectra are very similar to the complex of $\mathrm{Ni}^{2+}$-substituted alcohol dehydrogenase, which has an $\mathrm{S}_{2} \mathrm{~N}_{2}$ coordination environment in its complex with an external $\mathrm{N}$-donor ligand [32]. Similarity is also evident based on a comparison with $\mathrm{Ni}(\mathrm{II})$ glutathione complexes [37]. The Ni(II) sites in both ZnT8c variants are low-spin squareplanar or square-pyramidal as evidenced by a clear band at $490 \mathrm{~nm}$, and represent thiol coordination as evidenced by a ligand-to-metal charge transfer transition at $290 \mathrm{~nm}$. The site geometries are significantly different in the two variants, because of the opposite signs of the $290 \mathrm{~nm}$ band and the presence of additional bands in the individual cases. The three d-d electronic transitions in ZnT8cR suggest a more significant deviation from the planarity of the complex, while the low-energy CT band present only in ZnT8cW-apparently an S( $\pi$ ) $\rightarrow \mathrm{Ni}(\mathrm{II})$ transition-suggests different arrangements of sulfur donors in space. A second approach to characterize metal binding is to use chromophoric or fluorogenic chelating agents. We previously used the chromophoric chelating agent Zincon in competition with ZnT8c to investigate the affinity and stoichiometry of zinc binding [21]. Here, we employ this reagent and a fluorogenic $\mathrm{Zn}$ (II) chelating agent, FluoZin-3, to measure the binding of $\mathrm{Ni}(\mathrm{II})$ ions and probe the participation of sulfur ligands from cysteines following their chemical modification, extending the use of these reagents in (inorganic) chemical biology. Like $\mathrm{Zn}$ (II) binding, there is one $\mathrm{Ni}$ (II) binding site that is abolished when the cysteines are modified, leaving one site, which could be either the N-terminal 6xHis tag, which binds $\mathrm{Ni}$ (II) ions with an affinity of $700 \mathrm{nM}$ [38], or the other CTD site, or could reflect a distribution of nickel between both. The CTD forms a tetramer when the N-terminal 6xHis tag is removed [39]. In agreement with the investigations of others, we find that the CTD with the tag forms a dimer [19,21]. Investigating $\mathrm{Ni}(\mathrm{II})$ binding is also important for the biology of this transporter, because there are $\mathrm{Ni}^{2+}$ transporters in the CDF family [40] and nickel has been found in human islets [41], and therefore selectivities of the metal binding sites need to be understood. It is not only an issue of whether ZnT8 transports nickel, but also how the binding of other metal ions in the CTD affects zinc transport. Mismetalation in the CTD could modulate transporter function and have significant consequences on islet biology and glucose homeostasis. A case in point is cadmium. A single substitution of an Asp in the zinc transport site of YiiP to a His in human ZnT confers selectivity for zinc over cadmium [42]. However, a corollary of sulfur coordination in the metals sites is that cadmium, a thiophilic cation, is likely to bind in the CTD and affect the function 
of ZnT8, as it has been shown that cadmium accumulates in mouse $\beta$-cells and impairs their function [43]. In addition, the two variants have slightly different properties in their interactions with metal ions and it will be interesting to find out how this difference relates to the diabetes T2 risk and the antigenicity of the protein in diabetes T1.

\section{Material and Methods}

\subsection{Materials}

HEPES, iodoacetamide, Zincon sodium salt, $\mathrm{NaCl}$, hydrogen peroxide, $\mathrm{ZnCl}_{2}, \mathrm{KCl}$, $\mathrm{NiSO}_{4}$, gallium (99.9995\%), $\mathrm{NaN}_{3}, \mathrm{HNO}_{3} 70 \%$, methanol, acetic acid, and ethanol were purchased from Sigma Aldrich (Merck Life Science UK Ltd., Gillingham, UK); Tris hydrochloride (TRIS/HCl) from MP Biomedicals (Fisher Scientific UK, Loughborough Leicester, UK); 5,5'-dithio-bis-(2-nitrobenzoic acid) (DTNB; Ellman's reagent) from Invitrogen (Thermo Fisher Scientific UK, Ashford, UK); $\geq 18.2 \mathrm{M} \Omega \mathrm{cm}$ ultrapure water was obtained from an ELGA LabWater UK system (High Wycombe, UK).

\subsection{Protein Purification}

The ZnT8 CTDs (ZnT8c protein) were expressed and purified according to our established protocol [21]. Denaturing sodium dodecyl sulfate-polyacrylamide gel electrophoresis (SDS-PAGE) was performed according to the Invitrogen NuPAGE®specifications. Briefly, $5 \mu \mathrm{L}$ of protein sample (5-20 $\mu$ g protein) were mixed with $10 \mu \mathrm{L}$ of sample loading buffer (Invitrogen) and heated at $80^{\circ} \mathrm{C}$ for $14 \mathrm{~min}$. Samples were loaded into precast NuPAGE Novex $14 \%$ Bis-Tris $1.0 \mathrm{~mm}$ minigels (Invitrogen) with $5 \mu \mathrm{L}$ of Pre-stained SDS-PAGE Standards (Bio-Rad, Watford Hertfordshire, UK). Electrophoresis was performed at $25^{\circ} \mathrm{C}$ for approximately $55 \mathrm{~min}$ using a constant voltage $(200 \mathrm{~V})$ in a solution of NuPAGE SDS running buffer (Invitrogen) until the dye front reached the end of the $60 \mathrm{~mm}$ gel. Gels were washed three times in ultrapure water for $5 \mathrm{~min}$, stained twice in $100 \mathrm{~mL}$ of fixing solution (40\% methanol and $60 \%$ acetic acid), incubated in $100 \mathrm{~mL}$ of Coomassie R250 solution for $1 \mathrm{~h}$ and placed on a shaker for $30 \mathrm{~min}$. Dilute size exclusion fractions were concentrated using $15 \mathrm{~mL} 3 \mathrm{kDa}$ molecular mass cut-off centrifugal concentrators (Merck Millipore, Merck Life Science UK Ltd., Gillingham, UK). The concentration of pure ZnT8c protein was checked both spectroscopically using a Nanodrop 2000 (Thermo Scientific, Thermo Fisher Scientific UK, Ashford Kent, UK) instrument and spectrophotometrically using a modified Bradford protein assay. The extinction coefficients of 13,980 and $8480 \mathrm{M}^{-1} \mathrm{~cm}^{-1}$ for ZnT8cW and ZnT8cR, respectively, were calculated from the primary protein sequences [21].

\subsection{Elemental Analysis by Inductively Coupled Plasma-Mass Spectrometry}

Samples were analyzed using ICP-MS (PerkinElmer NexION 350D, Seer Green, Bucks, UK) equipped with a glass Meinhard nebulizer. The ICP-MS settings were: gas flow $1 \mathrm{~L} / \mathrm{min}$; auxiliary gas flow $1.2 \mathrm{~L} / \mathrm{min}$; plasma flow $18 \mathrm{~L} / \mathrm{min}$; RF power $1600 \mathrm{~W}$; cell gas flow He $4.1 \mathrm{~mL} / \mathrm{min}$. Elemental standards ( $\mathrm{Zn}$ and $\mathrm{Ni}$ ) in $2 \%(v / v) \mathrm{HNO}_{3}$ were used for calibration and detected as ${ }^{66} \mathrm{Zn}$ and ${ }^{60} \mathrm{Ni}$ isotopes. Prior to sample analysis, calibration curves for each element were constructed over the range 0.1-1000 $\mu \mathrm{g} / \mathrm{L}$. Linear regression correlation coefficients $\left(R^{2}\right)$ better than 0.9990 were obtained in all cases. A digestion procedure commonly applied to biological specimen was used: samples $(100 \mu \mathrm{L})$ were digested with $400 \mu \mathrm{L}$ of $75 \% \mathrm{HNO}_{3}$ and heated at $60{ }^{\circ} \mathrm{C}$ overnight, and then diluted for analysis with ultrapure water to a final $\mathrm{HNO}_{3}$ concentration of $2 \%$.

\subsection{Elemental Analysis by Total Reflection X-ray Fluorescence}

TXRF measurements were performed with a Bruker S2 PICOFOX TXRF (Bruker AXS Microanalysis $\mathrm{GmbH}$, Berlin, Germany) benchtop instrument equipped with molybdenum tube and silicon drift detector. The excitation source operated at $40 \mathrm{kV}$ and $650 \mu \mathrm{A}$. A gallium solution $(10 \mathrm{mg} / \mathrm{L})$ in nitric acid was used as internal standard for quantification. For each sample, $40 \mu \mathrm{L}$ of solution was prepared for TXRF analysis. Specimens were prepared by depositing $10 \mu \mathrm{L}$ of sample solution on the quartz glass sample carrier and 
drying at $50{ }^{\circ} \mathrm{C}$ on a heating plate. Each specimen was measured for $10 \mathrm{~min}$; duplicates of each sample were performed. TXRF spectra were inspected, all elements identified, and deconvoluted using the PICOFOX ${ }^{\mathrm{TM}}$ software. Elemental concentrations of the different elements were calculated by reference to the Ga standard in each sample.

\subsection{Determination of Metal Binding with Competing Chelating Agents}

The affinities of the $\mathrm{ZnT} 8 \mathrm{c}$ sites for $\mathrm{Ni}^{2+}$ were estimated by using two indicators: FluoZin-3 and Zincon. The stoichiometry between $\mathrm{Ni}^{2+}$ and either FluoZin-3 or Zincon was investigated by using two methods: Job's method [44] and the Complementary Approach [45]. The stoichiometries of the metal/protein complexes were obtained from a competition assay used to determine the zinc content of the protein [21]. To examine whether the metal ion is forming a complex with the indicator, a methanolic solution of FluoZin-3 or Zincon was mixed with an aqueous solution of metal ions for $1 \mathrm{~min}$ at different molar concentration ratios ranging from 1:4 to 1:50 (indicator:metal) at different $\mathrm{pH}$ values. The concentration of FluoZin-3 or Zincon ranged from 20 to $50 \mu \mathrm{M}$ while that of nickel was kept constant at $300 \mu \mathrm{M}$. The blank for indicator and nickel complex measurements was composed of methanol and water in a 1:1 ratio.

\subsection{Job's Method}

Job's method, also known as the method of continuous variation, is a simple analytical approach which determines the stoichiometry of two interacting components. In this method, the total molar concentration of two reactants is kept constant while their molar concentration ratios are continuously varied throughout the series of samples. According to Job's method, a peak in spectroscopic readout at a specific concentration ratio corresponds to the stoichiometry of the complex formed. In this experiment, an aqueous solution of nickel was mixed with a methanolic solution of the substance to be tested (FluoZin3/Zincon) at different molar concentration ratios ranging from 1:3 to 6:1 (indicator:metal) and after 3 min absorption spectra were measured against a blank composed of methanol and water in a 1:2 ratio.

\subsection{Complementary Approach}

For the complementary approach the molar concentration of indicator was continuously changed, while the concentration of nickel was kept constant in the samples with different molar concentration ratios ranging from 1:3 to 6:1 (indicator:metal). The concentration of the metal ion was $25 \mu \mathrm{M}$, while that of FluoZin-3 or Zincon were varied from 6 to $100 \mu \mathrm{M}$. The blank composition was the same as in the case of Job's method. Calculation of the complex stoichiometry is based on our mathematical approach [45]. Briefly, molar absorption coefficients for FluoZin-3 or Zincon and their complexes with $\mathrm{Ni}$ (II) were calculated by measuring a series of different concentrations of FluoZin-3 or Zincon with or without the metal ion. Based on these coefficients, theoretical lines were constructed representing the absorbances of the most probable integer stoichiometries and matched with measured data of the different indicator:nickel ratios to determine the stoichiometry.

\subsection{FluoZin-3 as a Fluorophore to Detect Nickel(II)}

The principle of this method is based on an increase in fluorescence when the indicator, which is generally employed for the determination of $\mathrm{Zn}(\mathrm{II})$, also binds $\mathrm{Ni}(\mathrm{II})$. The complex formation was determined spectrofluorometrically (Fluoroskan Ascent CF, Labsystems, ThermoFisher) using 96-well plates (Thermo Scientific). All experiments were performed with a buffer containing $50 \mathrm{mM}$ HEPES, $500 \mathrm{mM} \mathrm{KCl}$, and $100 \mathrm{mM}$ sucrose at $\mathrm{pH}$ values ranging from 6.0 to 8.0 . A stock solution of $100 \mathrm{mM} \mathrm{NiSO}_{4}$ was prepared in $10 \mathrm{~mL}$ of water and used for the experiments upon dilution with buffer. A stock solution of $1 \mathrm{mM}$ indicator in methanol was diluted with buffer to a final concentration of $70 \mu \mathrm{M}$. The indicator and the metal ions were mixed in buffer for $2 \mathrm{~min}$, the samples incubated for $1 \mathrm{~min}$ at $25^{\circ} \mathrm{C}$ 
in the dark and electronic absorption spectra measured (300-800 nm). Fluorescence was measured at $\lambda \mathrm{em}=520 \mathrm{~nm}$ and $\lambda \mathrm{ex}=480 \mathrm{~nm}$.

\subsection{Zincon as a Chromophore to Detect Nickel(II)}

Zincon, a complexing agent generally employed for the colorimetric determination of $\mathrm{Zn}$ (II) [46], can also be employed for the determination of Ni(II). The concentration of free Zincon was measured at $488 \mathrm{~nm}$ with a Jenway 7315 spectrophotometer (Chelmsford Essex, UK) using the extinction coefficient $\varepsilon_{488}=26,900 \mathrm{M}^{-1} \mathrm{~cm}^{-1}$ and a $0.5 \mathrm{~cm}$ path length quartz cuvette [21]. All experiments were performed in $50 \mathrm{mM} \mathrm{HEPES}, 300 \mathrm{mM} \mathrm{NaCl}$, and $100 \mathrm{mM}$ sucrose at $\mathrm{pH}$ values ranging from 6.0 to 8.0 with a methanolic Zincon solution at a final concentration of $70 \mu \mathrm{M}$. Concentrations of $\mathrm{Ni}$ (II) added were from 10 to $100 \mu \mathrm{M}$. Absorbance of the Zincon- $\mathrm{Ni}^{2+}$ complex was determined at $653 \mathrm{~nm}$.

\subsection{Thiol Assays}

A 5,5'-dithio-bis(2-nitrobenzoic acid) (DTNB) assay was used to quantify the free sulfhydryls at the C-terminus of ZnT8c proteins. The protein samples were adjusted to a final volume of $2 \mathrm{~mL}$ and to a final protein concentration of $2 \mu \mathrm{M}$ by using $500 \mathrm{mM}$ HEPES $\mathrm{pH} 8,300 \mathrm{mM} \mathrm{NaCl}$ and $100 \mathrm{mM}$ sucrose. After the addition of DTNB to a final concentration of $1 \mathrm{mM}$ the samples were vortexed for $1 \mathrm{~min}$ and incubated at $20{ }^{\circ} \mathrm{C}$ for $15 \mathrm{~min}$. The production of 2-nitro-5-thiobenzoate (TNB) was measured at $412 \mathrm{~nm}$, using the extinction coefficient $\varepsilon_{412}=14,150 \mathrm{M}^{-1} \mathrm{~cm}^{-1}$. The blank contained deionized water. Iodoacetamide and hydrogen peroxide were used to alkylate or oxidize the sulfhydryls on the cysteine side chains. Alkylation was confirmed by measuring no free sulfhydryl in the protein with DTNB. For both reactants, $0.5 \mathrm{M}$ stock solutions were prepared in ultrapure water. Protein samples were incubated with $15 \mathrm{mM}$ of either iodoacetamide or hydrogen peroxide for $1 \mathrm{~h}$ at $20^{\circ} \mathrm{C}$.

\subsection{Protein Competition Assays}

Competition assays were performed by using both indicators (FluoZin-3 and Zincon). ZnT8c protein $(5 \mu \mathrm{M})$ was added to the mixture with the indicators, both at working concentrations of $70 \mu \mathrm{M}$. The solutions were mixed for $2 \mathrm{~min}$ and the absorbance/fluorescence measured. Binding stoichiometries were analyzed by extrapolation of the linear portion of the titration curves and comparison with the buffer-only controls. The three cysteines at the C-terminus of ZnT8c were acetylated using iodoacetamide to evaluate whether they contribute to metal binding. Iodoacetamide (stock solution $0.5 \mathrm{M}$ in water) was added to the mixture of $5 \mu \mathrm{M} \mathrm{ZnT8c}$ and incubated for $1 \mathrm{~h}$ at $20^{\circ} \mathrm{C}$, prior to the competition assays. Statistical analyses were performed using the software GraphPad Prism version 8 for Windows (GraphPad Software, La Jolla, CA, USA).

\subsection{Far-UV Absorbance and Circular Dichroism Spectroscopy}

Protein UV and CD spectra were acquired on an Chirascan Plus spectrometer (Applied Photophysics, Leatherhead, UK). Protein samples of either ZnT8c variant were diluted to $35 \mu \mathrm{M}$ in $10 \mathrm{mM}$ HEPES, $\mathrm{pH} 8,60 \mathrm{mM} \mathrm{NaCl}, 20 \mathrm{mM}$ sucrose and incubated with 0-2 molar equivalents of $\mathrm{Zn}^{2+}$ for $20 \mathrm{~min}$ at $21^{\circ} \mathrm{C}$. A $10 \mathrm{~mm}$ Quartz Suprasil rectangular cuvette (Starna Scientific, Ltd., Ilford, UK) was employed in the spectral region 230-800 $\mathrm{nm}$. The instrument was flushed continuously with nitrogen gas. The following parameters were employed: $2 \mathrm{~nm}$ spectral bandwidth, 1 or $2 \mathrm{~nm}$ step size and 1 or $1.5 \mathrm{~s}$ accumulation time-per-point. The Near-UV-CD spectra were smoothed using Chirascan Pro-Data Viewer software v4.2.15 (Applied Photophysics) with a Savitsky-Golay smoothing factor of 4. The UV and CD spectra were corrected with appropriate buffer solutions. Unless otherwise stated, all spectra were measured at $23^{\circ} \mathrm{C}$. Data are presented using Origin V6 (OriginLab Corp.). The cuvette was washed with a mixture of concentrated nitric acid and ethanol $(50: 50, v / v)$ and dried using nitrogen gas before and between sample measurements to 
prevent cross contamination. Measurement of each sample was repeated after $10 \mathrm{~min}$ to determine whether spectra changed due to protein aggregation.

\subsection{C-Terminal and N-Terminal Peptide Syntheses}

For peptide synthesis, the dedicated Fmoc protected amino acids and 2-(1H-benzotriazole1-yl)-1,1,3,3-tetramethyluronium hexafluorophosphate (HBTU) were purchased from NovaBiochem (Merck Sp., Warszawa, Poland). The TentaGel S RAM and TentaGel S PHBLys(Boc)-Fmoc resins were obtained from RAPP Polymere (Tübingen, Germany). The solvents of piperidine, triisopropylsilane (TIS), $N, N$-diisopropylethylamine (DIPEA), 1,2ethanedithiol (EDT) and trifluoroacetic acid (TFA) were received from Sigma (SigmaAldrich Sp., Poznan, Poland). Dimethylformamide (DMF) was purchased from Carl Roth (Karlsruhe, Germany), acetonitrile from Avantor (VWR Sp., Gdańsk, Poland) and diethyl ether from Chempur Feinchemikalien (Karlsruhe, Germany). The Ac-MYHCHSGS-NH2 (ZnT8N) and Ac-PDCLFCEDPCD (ZnT8C) peptides were synthesized on a Liberty 1 automated peptide synthesizer (CEM Corporation, Buckingham, UK) according to the standard solid-phase Fmoc strategy [47]. The acetylation step was performed after the automated synthesis by incubating the resin for $10 \mathrm{~min}$ in $10 \%$ acetic anhydride. The peptides were cleaved from the resin with a cocktail composed of 94:1:2.5:2.5 $(v / v / v / v)$ TFA/TIS/EDT/water. After $2 \mathrm{~h}$, the peptides were precipitated from the solution with cold diethyl ether and then lyophilized. The ZnT8N peptide was purified by reversed-phase high-performance liquid chromatography (RP-HPLC; Waters Sp. Warszawa, Poland) on a Ascentis RP-Amide (Supelco-Sigma-Aldrich) and the ZnT8C peptide was purified using RP-HPLC (Knauer Polska, Warszawa, Poland) on a C18 Eurospher II column (Knauer). The eluting solvent A was $0.1 \%$ TFA in water, and solvent B was $0.1 \%$ TFA in $90 \%$ acetonitrile. The high purity of both peptides was confirmed by electrospray ionization mass spectrometry (ESI-MS; Premier, Waters) and potentiometry.

\subsection{Potentiometry}

Potentiometric titrations were performed on a 907 Titrando Automatic Titrator (Metrohm, Herisau, Switzerland) with a Biotrode combined glass electrode (Metrohm). The electrode was calibrated daily by titrating an argon-bubbled $4 \mathrm{mM} \mathrm{HNO}_{3} / 96 \mathrm{mM} \mathrm{KNO}_{3}$ solution with $0.1 \mathrm{M} \mathrm{NaOH}$. The solubility of the peptide in the $\mathrm{HNO}_{3} / \mathrm{KNO}_{3}$ solution was verified using UV/Vis spectroscopy. Pure peptide, stored anaerobically, was dissolved in $7.5 \mathrm{~mL}$ of $0.4 \mathrm{mM} \mathrm{HNO}_{3} / 99.6 \mathrm{mM} \mathrm{KNO}_{3}$ solution to a final concentration of $180 \mu \mathrm{M}$ and incubated with 0-0.9 molar equivalents of $\mathrm{Zn}^{2+}\left(\mathrm{ZnCl}_{2}\right)$ at $25^{\circ} \mathrm{C}$ for $5 \mathrm{~min}$ before potentiometric titrations with $0.1 \mathrm{M} \mathrm{NaOH}$. All experiments were performed under argon at $25^{\circ} \mathrm{C}$. The SUPERQUAD and HYPERQUAD programs [48] were used to analyze the data and generate the species distribution diagrams. The formation of complexes was characterized by the general equilibrium process:

$$
\begin{gathered}
p M+q H+r L \stackrel{\beta M p H q L r}{\rightarrow} M p H q L r \\
\beta M p H q L r=\frac{[M p H q L r]}{[M] p[H] q[L] r}
\end{gathered}
$$

where $M$ represents metal, i.e., $\mathrm{Zn}^{2+}, L$ represents deprotonated ligand, i.e., the 11-residue ZnT8 C-terminal peptide, $H$ represents protons and $\beta$ is the stability constant of a complex.

\section{Conclusions}

We demonstrate that the cytosolic CTD of ZnT8 binds nickel ions with a stoichiometry similar to zinc ion binding. Titration of the protein with nickel ions in the presence and absence of cysteine modification and spectroscopic features indicate binding to sulfur in coordination environments that differ significantly in the two variants, revealing for the first time structural differences between the two variants and sulfur coordination in zinc transporter biochemistry, possibly also involving redox biology in human ZnT zinc 
transporters. We had shown previously that the $\mathrm{W} / \mathrm{R}$ mutation in the CTD affecting diabetes risk influences metal affinity and elicits differences in physical properties of the protein [21]. How the variants alter the risk of developing diabetes remains an important issue. Our investigations show that this question is related to the specificity and mode of metal binding in the C-terminal domain. Since the only cysteines present in the CTD are the ones in the C-terminus, the participation of these residues, which are typical for the vesicular $\mathrm{ZnT}$ proteins, in metal binding is demonstrated as now supported by cryo-EM investigations and high affinity binding of zinc in the absence of added zinc [20]. The metal binding with the participation of cysteine ligands is important for other vesicular transporters (ZnT2, ZnT3 and ZnT4) involved in a wide variety of physiological processes and suggests that other thiophilic metal ions such as cadmium could interfere with the physiological processes in which these transporters are involved. The cryo-EM structure of human ZnT8 demonstrates that the $\mathrm{N}$-terminus connects the metal sites with transmembrane helix 1 (TM1), which together with TM2,4 \& 5 is important for the dynamics of the protein in transport [20]. Therefore, there is a conduit that transmits metal binding in the CTD - and the differential effects of the two different amino acids in the variants, which we show affect metal binding to the zinc transporting function of the protein. The $\mathrm{N}$-terminal tail and the type of metal ions bound and the occupancy of the metal binding sites in the CTD are all critical aspects of the functions of the vesicular ZnT transporters.

Author Contributions: Conceptualization, W.M., W.B.; methodology, M.C.C., D.S.P., W.M., W.B., P.M.; validation, M.C.C., D.S.P., R.K.; formal analysis, M.C.C., R.K., W.M., W.B.; investigation, M.C.C., R.K., D.S.P.; resources, W.M., W.B., P.M.; data curation, M.C.C., D.S.P., W.M.; writing-original draft preparation, M.C.C.; writing-review and editing, M.C.C., W.M., D.S.P., W.B.; visualization, M.C.C., D.S.P.; supervision, W.M., W.B., P.M.; project administration, W.M., W.B.; funding acquisition, W.M., W.B. All authors have read and agreed to the published version of the manuscript.

Funding: The authors acknowledge the "London Metallomics Facility" funded by the Wellcome Trust (grant reference 202902/Z/16/Z) and King's College London, and the project EFSA-CDN (No.CZ.02.1.01/0.0/0.0/16_019/0000841). D.S.P. was supported by a PhD studentship from the Medical Research Council.

Institutional Review Board Statement: Not applicable.

Data Availability Statement: All data are available upon request from the authors.

Acknowledgments: Maria Carmen Catapano was supported by a student mobility scheme under the European Union ERASMUS+ Programme. We thank Peter Chivers, Durham University, Durham, UK for bringing the application of FluoZin-3 as a nickel ion sensor to our attention, Sukhi Bansal, Department of Pharmacy, School of Cancer and Pharmaceutical Sciences, King's College London for the synthesis of the N-terminal peptide and Tam T. T. Bui, Biomolecular Spectroscopy Centre, King's College London for acquisition and processing of CD spectra. This article is dedicated to the memory of Deborah Zamble and her contributions to the understanding of nickel metalloproteins. (https://www.chemistry.utoronto.ca/news/remembering-deborah-zamble).

Conflicts of Interest: The authors declare no conflict of interest.

\section{Abbreviations}

$\varepsilon \quad$ extinction coefficient;

$\lambda \max \quad$ wavelength of maximal emission;

CD circular dichroism;

cDNA complementary DNA;

CTD C-terminal domain;

CDF cation diffusion facilitator;

TMD transmembrane domain;

DTNB 5,5'-dithio-bis-(2-nitrobenzoic acid);

DTT dithiothreitol; 


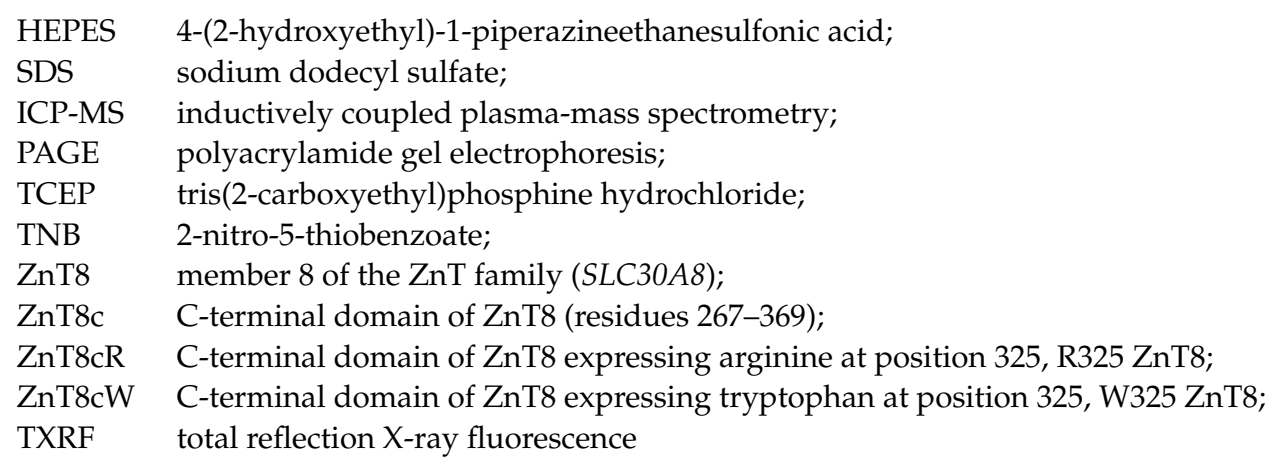

\section{References}

1. Hogstrand, C.; Fu, D. Zinc. In Binding, Transport and Storage of Metal Ions in Biological Cells; Maret, W., Wedd, A.G., Eds.; Royal Society of Chemistry: Cambridge, UK, 2014; pp. 666-694.

2. Kambe, T.; Tsuji, T.; Hashimoto, A.; Itsumura, N. The Physiological, Biochemical, and Molecular Roles of Zinc Transporters in Zinc Homeostasis and Metabolism. Physiol. Rev. 2015, 95, 749-784. [CrossRef] [PubMed]

3. Davidson, H.W.; Wenzlau, J.M.; O’Brien, R.M. Zinc transporter 8 (ZnT8) and beta cell function. Trends Endocrinol. Metab. 2014, 25, 415-424. [CrossRef] [PubMed]

4. Solomou, A.; Philippe, E.; Chabosseau, P.; Migrenne-Li, S.; Gaitan, J.; Lang, J.; Magnan, C.; Rutter, G.A. Over-expression of Slc30a8/ZnT8 selectively in the mouse alpha cell impairs glucagon release and responses to hypoglycemia. Nutr. Metab. 2016, 13, 46. [CrossRef] [PubMed]

5. Lu, M.; Fu, D. Structure of the zinc transporter YiiP. Science 2007, 317, 1746-1748. [CrossRef] [PubMed]

6. Lu, M.; Chai, J.; Fu, D. Structural basis for autoregulation of the zinc transporter YiiP. Nat. Struct. Mol. Biol. 2009, 16, 1063-1067. [CrossRef] [PubMed]

7. Coudray, N.; Valvo, S.; Hu, M.; Lasala, R.; Kim, C.; Vink, M.; Zhou, M.; Provasi, D.; Filizola, M.; Tao, J.; et al. Inward-facing conformation of the zinc transporter YiiP revealed by cryoelectron microscopy. Proc. Natl. Acad. Sci. USA 2013, 110, $2140-2145$. [CrossRef]

8. Cherezov, V.; Höfer, N.; Szebenyi, D.M.E.; Kolaj, O.; Wall, J.G.; Gillilan, R.; Srinivasan, V.; Jaroniec, C.P.; Caffrey, M. Insights into the mode of action of a putative zinc transporter CzrB in Thermus thermophilus. Structure 2008, 16, 1378-1388. [CrossRef]

9. Higuchi, T.; Hattori, M.; Tanaka, Y.; Ishitani, R.; Nureki, O. Crystal structure of the cytosolic domain of the cation diffusion facilitator family protein. Proteins 2009, 76, 768-771. [CrossRef]

10. Uebe, R.; Keren-Khadmy, N.; Zeytuni, N.; Katzmann, E.; Navon, Y.; Davidov, G.; Bitton, R.; Plitzko, J.M.; Schüler, D.; Zarivach, R. The dual role of MamB in magnetosome membrane assembly and magnetite biomineralization. Mol. Microbiol. 2018, 107, 542-557. [CrossRef] [PubMed]

11. Zeytuni, N.; Offer, T.; Davidov, G.; Zarivach, R. Crystallization and preliminary crystallographic analysis of the C-terminal domain of MamM, a magnetosome-associated protein from Magnetospirillum gryphiswaldense MSR-1. Acta Crystallogr. Sect. F Struct. Biol. Cryst. Commun. 2012, 68, 927-930. [CrossRef]

12. Udagedara, S.R.; La Porta, D.M.; Spehar, C.; Purohit, G.; Hein, M.J.A.; Fatmous, M.E.; Casas Garcia, G.P.; Ganio, K.; McDevitt, C.A.; Maher, M.J. Structural and functional characterizations of the C-terminal domains of CzcD proteins. J. Inorg. Biochem. 2020, 208, 111087. [CrossRef] [PubMed]

13. Krężel, A.; Maret, W. Zinc-buffering capacity of a eukaryotic cell at physiological pZn. J. Biol. Inorg. Chem. 2006, 11, 1049-1062. [CrossRef] [PubMed]

14. Vinkenborg, J.L.; Nicolson, T.J.; Bellomo, E.A.; Koay, M.S.; Rutter, G.A.; Merkx, M. Genetically encoded FRET sensors to monitor intracellular $\mathrm{Zn}^{2+}$ homeostasis. Nat. Methods 2009, 6, 737-740. [CrossRef] [PubMed]

15. Maret, W. Analyzing free zinc(II) ion concentrations in cell biology with fluorescent chelating molecules. Metallomics 2015, 7 , 202-211. [CrossRef]

16. Chabosseau, P.; Woodier, J.; Cheung, R.; Rutter, G.A. Sensors for measuring subcellular zinc pools. Metallomics 2018, 10, 229-239. [CrossRef]

17. Marszałek, I.; Goch, W.; Bal, W. Ternary Zn(II) Complexes of FluoZin-3 and the Low Molecular Weight Component of the Exchangeable Cellular Zinc Pool. Inorg. Chem. 2018, 57, 9826-9838. [CrossRef] [PubMed]

18. Goch, W.; Bal, W. Stochastic or Not? Method to Predict and Quantify the Stochastic Effects on the Association Reaction Equilibria in Nanoscopic Systems. J. Phys. Chem. A 2020, 124, 1421-1428. [CrossRef] [PubMed]

19. Daniels, M.J.; Jagielnicki, M.; Yeager, M. Structure/Function analysis of human ZnT8 (SLC30A8): A diabetes risk factor and zinc transporter. Curr. Res. Struct. Biol. 2020, 2, 144-155. [CrossRef]

20. Xue, J.; Xie, T.; Zeng, W.; Jiang, Y.; Bai, X.C. Cryo-EM structures of human ZnT8 in both outward- and inward-facing conformations. eLife 2020, 9, e58823. [CrossRef]

21. Parsons, D.S.; Hogstrand, C.; Maret, W. The C-terminal cytosolic domain of the human zinc transporter ZnT8 and its diabetes risk variant. FEBS J. 2018, 285, 1237-1250. [CrossRef] 
22. Boesgaard, T.W.; Žilinskaite, J.; Vänttinen, M.; Laakso, M.; Jansson, P.A.; Hammarstedt, A.; Smith, U.; Stefan, N.; Fritsche, A.; Häring, H.; et al. The common SLC30A8 Arg325Trp variant is associated with reduced first-phase insulin release in 846 non-diabetic offspring of type 2 diabetes patients-The EUGENE2 study. Diabetologia 2008, 51, 816-820. [CrossRef]

23. Merriman, C.; Huang, Q.; Rutter, G.A.; Fu, D. Lipid-tuned Zinc Transport Activity of Human ZnT8 Protein Correlates with Risk for Type-2 Diabetes. J. Biol. Chem. 2016, 291, 26950-26957. [CrossRef]

24. Kim, I.; Kang, E.S.; Yim, Y.S.; Ko, S.J.; Jeong, S.H.; Rim, J.H.; Kim, Y.S.; Ahn, C.W.; Cha, B.S.; Lee, H.C.; et al. A low-risk ZnT-8 allele (W325) for post-transplantation diabetes mellitus is protective against cyclosporin A-induced impairment of insulin secretion. Pharm. J. 2011, 11, 191-198. [CrossRef]

25. Carvalho, S.; Molina-Lopez, J.; Parsons, D.; Corpe, C.; Maret, W.; Hogstrand, C. Differential cytolocation and functional assays of the two major human SLC30A8 (ZnT8) isoforms. J. Trace Elem. Med. Biol. 2017, 44, 116-124. [CrossRef] [PubMed]

26. Sala, D.; Giachetti, A.; Rosato, A. Insights into the Dynamics of the Human Zinc Transporter ZnT8 by MD Simulations. J. Chem. Inf. Model. 2021, 61, 901-912. [CrossRef] [PubMed]

27. Wenzlau, J.M.; Liu, Y.; Yu, L.; Moua, O.; Fowler, K.T.; Rangasamy, S.; Walters, J.; Eisenbarth, G.S.; Davidson, H.W.; Hutton, J.C. A common nonsynonymous single nucleotide polymorphism in the SLC30A8 gene determines ZnT8 autoantibody specificity in type 1 diabetes. Diabetes 2008, 57, 2693-2697. [CrossRef]

28. Zhao, J.; Bertoglio, B.A.; Devinney, M.J., Jr.; Dineley, K.E.; Kay, A.R. The interaction of biological and noxious transition metals with the zinc probes FluoZin-3 and Newport Green. Anal. Biochem. 2009, 384, 34-41. [CrossRef] [PubMed]

29. Marszałek, I.; Krężel, A.; Goch, W.; Zhukov, I.; Paczkowska, I.; Bal, W. Revised stability constant, spectroscopic properties and binding mode of $\mathrm{Zn}$ (II) to FluoZin-3, the most common zinc probe in life sciences. J. Inorg. Biochem. 2016, 161, 107-114. [CrossRef] [PubMed]

30. Kocyła, A.; Pomorski, A.; Krężel, A. Molar absorption coefficients and stability constants of Zincon metal complexes for determination of metal ions and bioinorganic applications. J. Inorg. Biochem. 2017, 176, 53-65. [CrossRef]

31. Sydor, A.M.; Lebrette, H.; Ariyakumaran, R.; Cavazza, C.; Zamble, D.B. Relationship between Ni(II) and Zn(II) coordination and nucleotide binding by the Helicobacter pylori [NiFe]-hydrogenase and urease maturation factor HypB. J. Biol. Chem. 2014, 289, 3828-3841. [CrossRef] [PubMed]

32. Dietrich, H.; Maret, W.; Kozlowski, H.; Zeppezauer, M. Active site-specifically reconstituted nickel(II) horse liver alcohol dehydrogenase: Optical spectra of binary and ternary complexes with coenzymes, coenzyme analogues, substrates, and inhibitors. J. Inorg. Biochem. 1981, 14, 297-311. [CrossRef]

33. Krężel, A.; Wójcik, J.; Maciejczyk, M.; Bal, W. May GSH and L-His contribute to intracellular binding of zinc? Thermodynamic and solution structural study of a ternary complex. Chem. Commun. 2003, 704-705. [CrossRef] [PubMed]

34. Robertson, R.P.; Harmon, J.; Tran, P.O.; Poitout, V. Beta-cell glucose toxicity, lipotoxicity, and chronic oxidative stress in type 2 diabetes. Diabetes 2004, 53 (Suppl. 1), S119-S124. [CrossRef]

35. Árus, D.; Dancs, Á.; Nagy, N.V.; Gajda, T. A comparative study on the possible zinc binding sites of the human ZnT3 zinc transporter protein. Dalton Trans. 2013, 42, 12031-12040. [CrossRef] [PubMed]

36. Maret, W.; Vallee, B.L. Cobalt as probe and label of proteins. Methods Enzymol. 1993, 226, 52-71.

37. Krężel, A.; Szczepanik, W.; Sokołowska, M.; Jeżowska-Bojczuk, M.; Bal, W. Correlations between complexation modes and redox activities of Ni(II)-GSH complexes. Chem. Res. Toxicol. 2003, 16, 855-864. [CrossRef] [PubMed]

38. Nieba, L.; Nieba-Axmann, S.E.; Persson, A.; Hamalainen, M.; Edebratt, F.; Hansson, A.; Lidholm, J.; Magnusson, K.; Karlsson, A.F.; Pluckthun, A. BIACORE analysis of histidine-tagged proteins using a chelating NTA sensor chip. Anal. Biochem. 1997, 252, 217-228. [CrossRef] [PubMed]

39. Ullah, R.; Shehzad, A.; Shah, M.A.; De March, M.; Ismat, F.; Iqbal, M.; Onesti, S.; Rahman, M.; McPherson, M.J. C-Terminal Domain of the Human Zinc Transporter hZnT8 Is Structurally Indistinguishable from Its Disease Risk Variant (R325W). Int. J. Mol. Sci. 2020, 21, 926. [CrossRef] [PubMed]

40. Cubillas, C.; Vinuesa, P.; Tabche, M.L.; Garcia-de los Santos, A. Phylogenomic analysis of Cation Diffusion Facilitator proteins uncovers $\mathrm{Ni}^{2+} / \mathrm{Co}^{2+}$ transporters. Metallomics 2013, 5, 1634-1643. [CrossRef]

41. Wong, W.P.; Allen, N.B.; Meyers, M.S.; Link, E.O.; Zhang, X.; MacRenaris, K.W.; El Muayed, M. Exploring the Association Between Demographics, SLC30A8 Genotype, and Human Islet Content of Zinc, Cadmium, Copper, Iron, Manganese and Nickel. Sci. Rep. 2017, 7, 473. [CrossRef] [PubMed]

42. Hoch, E.; Lin, W.; Chai, J.; Hershfinkel, M.; Fu, D.; Sekler, I. Histidine pairing at the metal transport site of mammalian ZnT transporters controls $\mathrm{Zn}^{2+}$ over $\mathrm{Cd}^{2+}$ selectivity. Proc. Natl. Acad. Sci. USA 2012, 109, 7202-7207. [CrossRef] [PubMed]

43. El Muayed, M.; Raja, M.R.; Zhang, X.; MacRenaris, K.W.; Bhatt, S.; Chen, X.; Urbanek, M.; O'Halloran, T.V.; Lowe, W.L., Jr. Accumulation of cadmium in insulin-producing beta cells. Islets 2012, 4, 405-416. [CrossRef]

44. Job, P. Recherches sur la formation des complexes minéraux en solution, et sur leur stabilité. Ann. Chim. 1928, 9, $113-203$.

45. Filipsky, T.; Riha, M.; Hrdina, R.; Vavrova, K.; Mladěnka, P. Mathematical calculations of iron complex stoichiometry by direct UV-Vis spectrophotometry. Bioorganic Chem. 2013, 49, 1-8. [CrossRef]

46. Sabel, C.E.; Neureuther, J.M.; Siemann, S. A spectrophotometric method for the determination of zinc, copper, and cobalt ions in metalloproteins using Zincon. Anal. Biochem. 2010, 397, 218-226. [CrossRef] 
47. Fields, G.B. Introduction to peptide synthesis. Curr. Protoc. Protein Sci. 2001, 26, 18.1.1-18.1.9. [CrossRef] [PubMed]

48. Gans, P.; Sabatini, A.; Vacca, A. Investigation of equilibria in solution. Determination of equilibrium constants with the HYPERQUAD suite of programs. Talanta 1996, 43, 1739-1753. [CrossRef] 